\title{
The initial errors that induce a significant "spring predictability barrier" for El Niño events and their implications for target observation: results from an earth system model
}

\author{
Wansuo Duan ${ }^{1,3} \cdot$ Junya $\mathrm{Hu}^{1,2}$
}

Received: 11 October 2014 / Accepted: 2 August 2015 / Published online: 11 August 2015

(C) The Author(s) 2015. This article is published with open access at Springerlink.com

\begin{abstract}
The National Center for Atmospheric Research Community Earth System Model is used to study the "spring predictability barrier" (SPB) problem for El Niño events from the perspective of initial error growth. By conducting perfect model predictability experiments, we obtain two types of initial sea temperature errors, which often exhibit obvious season-dependent evolution and cause a significant SPB when predicting the onset of El Niño events bestriding spring. One type of initial errors possesses a sea surface temperature anomaly (SSTA) pattern with negative anomalies in the central-eastern equatorial Pacific, plus a basin-wide dipolar subsurface temperature anomaly pattern with negative anomalies in the upper layers of the eastern equatorial Pacific and positive anomalies in the lower layers of the western equatorial Pacific. The other type consists of an SSTA component with positive anomalies over the southeastern equatorial Pacific, plus a large-scale zonal dipole pattern of the subsurface temperature anomaly with positive anomalies in the upper layers of the eastern equatorial Pacific and negative anomalies in the lower layers of the central-western equatorial Pacific. Both exhibit a La Niña-like evolving mode and cause an under-prediction for Niño-3 SSTA of El Niño events. For the former initial error type, the resultant prediction errors
\end{abstract}

Wansuo Duan

duanws@lasg.iap.ac.cn

1 State Key Laboratory of Numerical Modeling for Atmospheric Sciences and Geophysical Fluid Dynamics (LASG), Institute of Atmospheric Physics, Chinese Academy of Sciences, Beijing 100029, China

2 University of Chinese Academy of Sciences, Beijing 100049, China

3 Joint Center for Global Change Studies, Beijing 100875, China grow in a manner similar to the behavior of the growth phase of La Niña; while for the latter initial error type, they experience a process that is similar to El Niño decay and transition to a La Niña growth phase. Both two types of initial errors cause negative prediction errors of Niño-3 SSTA for El Niño events. The prediction errors for Niño-3 SSTA are mainly due to the contribution of initial sea temperature errors in the large-error-related regions in the upper layers of the eastern tropical Pacific and/or in the lower layers of the western tropical Pacific. These regions may represent "sensitive areas" for El Niño-Southern Oscillation (ENSO) predictions, thereby providing information for target observations to improve the forecasting skill of ENSO.

Keywords El Niño events - Spring predictability barrier · Initial errors $\cdot$ Target observation

\section{Introduction}

El Niño-Southern Oscillation (ENSO) describes the extreme sea surface warming events that occur in the eastern tropical Pacific Ocean accompanied by large-scale atmospheric circulation anomalies (Philander 1983, 1990). Although ENSO originates and develops mainly in the tropical Pacific, it is capable of bringing climate variability to various parts of the globe through teleconnection and resulting in serious societal and economic consequences (Bjerknes 1969; Ropelewski and Halpert 1987; Hoerling et al. 1997; Trenberth et al. 1998). Accordingly, we as a research community are continually motivated to improve the forecasting skill of ENSO.

With the development of ENSO-related theories, observing systems and numerical models, there has been encouraging progress in our understanding and prediction 
of ENSO (Wang and Picaut 2004; Wang and Fiedler 2006), and generally it is skillfully predictable with a 1 -year lead time in hindcast experiments (Chen and Cane 2008; Jin et al. 2008). However, considerable uncertainties still exist in realistic ENSO predictions; in particular, the influence of the so-called "spring predictability barrier" (SPB) for El Niño (Latif et al. 1994, 1998; Kirtman et al. 2002; Luo et al. 2005, 2008; Jin et al. 2008). This barrier manifests as a sharp drop-off in the monthly persistence of observed oceanic and atmospheric index associated with ENSO across boreal spring, and in numerical prediction models it appears as a sudden decrease (or increase) of the anomaly correlation coefficient (ACC) (or RMSE: root-mean-square error), regardless of the starting month (Webster and Yang 1992; Webster 1995; Torrence and Webster 1998; Luo et al. 2008). From the perspective of error growth, a "significant SPB" refers to the phenomenon that ENSO forecasting has a large prediction error; and in particular, a prominent error growth occurs during boreal spring when the prediction is made before and throughout that spring (Mu et al. 2007a, b; Duan et al. 2009; Duan and Wei 2012).

Agreement regarding the cause of the SPB has yet to be reached, although considerable efforts have been made in studying this phenomenon. Some studies argue that the SPB is an intrinsic characteristic of ENSO forecasting. Because the signal-to-noise ratio for SST tends to be lowest in spring, even additional observations cannot change the fact of the low signal in spring (Xue et al. 1994; Samelson and Tziperman 2001). Others, meanwhile, believe that the SPB arises from the growth of initial errors. Chen et al. $(1995,2004)$ suggest that ENSO predictions depend more on the initial conditions than on unpredictable noise, and hence the predictability of ENSO across spring can be greatly enhanced through improving the initialization. Moore and Kleeman (1996) investigated the seasondependent evolutions of initial errors related to SPB by using the linear singular vector (LSV) method, and Xue et al. (1997a, b) also applied LSV to ENSO predictability studies.

Mu et al. (2007a) demonstrated that the SPB may be a result of the combined effect of the climatological annual cycle, the El Niño event itself and the initial error pattern. In terms of the third factor, Mu et al. (2007b) used the Zebiak-Cane model (ZC model; Zebiak and Cane 1987) along with the conditional nonlinear optimal perturbation (CNOP) approach (Mu et al. 2003) to explore the initial errors that cause a significant SPB. Yu et al. (2009, 2012) further recognized two kinds of CNOP-type initial errors, which show a large-scale zonal dipolar pattern for the sea surface temperature anomaly (SSTA) component and a basin wide deepening or shoaling along the equator for the thermocline depth anomaly, and similar CNOP-like initial errors also exist in realistic ENSO predictions (Duan et al. 2009; Duan and Wei 2012). All these studies attempt to reveal the initial error that induces a significant SPB for El Niño events most probably, and identify the location in which additional observations should be a priority for improving the El Niño forecast skill. However, the results were obtained from the ZC model, which is an anomaly coupled model of intermediate-complexity and only considers the interannual variability of the tropical Pacific. In particular, they focused on the SSTA component of the initial errors and did not consider the role of subsurface temperatures in yielding the SPB, due to the limitation of the simplicity of the ZC model.

In fact, subsurface processes play an important role not only in the evolution of the ENSO life cycle, but also in ENSO predictions. On the one hand, observations show that the movement of upper-ocean warm water in the equatorial Pacific is closely related to ENSO events. The buildup of warm water volume (WWV) in the equatorial Pacific is a necessary precondition for the development of ENSO (Wyrtki 1975, 1985; Cane et al. 1986; Zebiak and Cane 1987; Zebiak 1989; Jin 1997a). Ramesh and Murtugudde (2013) stated that subsurface processes can be a fundamental driver for the onset of ENSO, whereas the SSTA follows later, serving as the surface manifestation of the subsurface temperature anomaly. Zelle et al. (2004) showed that there are two pathways for the thermocline depth anomaly leading to SST anomalies. One is the local "upwelling pathway" in which the SSTA is directly related to thermocline depth anomalies over the eastern equatorial Pacific, and the other "wind coupling pathway" provides a remote coupling through wave dynamics. Moreover, most theoretical ENSO oscillator models emphasize the importance of oceanic wave propagation processes associated with the upperocean heat content (OHC) anomalies (Suarez and Schopf 1988; Battisti and Hirst 1989; Weisberg and Wang 1997; Picaut et al. 1997). In particular, Jin (1997a, b) proposed that it is the phase lag between the zonal mean thermocline depth over the entire equatorial Pacific and the SST anomaly in the eastern Pacific that leads to an oscillation of ENSO. Generally, the predictability of ENSO mainly comes from the oceanic memory associated with subsurface temperature anomalies along the equatorial thermocline (Zebiak 1989). Variations in the equatorial WWV anomalies or the heat content anomalies of the equatorial Pacific precede ENSO SSTA variability by two to three seasons, so that they can serve as reliable predictors of Niño-3 SST (Meinen and Mcphaden 2000; Hasegawa and Hanawa 2003). Consistent with the phase relationship, there is a winter prediction barrier for the WWV (or OHC) anomalies, rather than a spring barrier. As a consequence, accurate initialization for sea level heights or $\mathrm{OHC}$ and correct prediction of subsurface signals can help to reduce the 
SPB (Clarke and Van Gorder 2003; Mcphaden 2003; Yu and Kao 2007; Luo et al. 2005, 2008).

In the above context, the following questions arise: What kinds of initial errors often cause the SPB in a more complex earth system model (ESM)? What is the dynamical mechanism responsible for error growth? In particular, what is the role of initial subsurface temperature errors in the occurrence of SPB? Motivated by these questions, in this study we use an ESM to explore the initial errors that cause a significant SPB for El Niño events, and suggest a possible mechanism responsible for the initial error growth by performing perfect model predictability experiments.

The remainder of this paper is organized as follows: First, in Sect. 2, we introduce the ESM, followed by the experimental strategy in Sect. 3. In Sect. 4, two types of initial errors that often yield a significant SPB for El Niño forecasts are identified. Then, in Sect. 5, we provide dynamical explanations for the season-dependent evolution of prediction errors caused by the two types of initial errors. In Sect. 6, we reveal some implications of the initial errors associated with the SPB in terms of target observations for El Niño events; and then to close, we summarize the study and offer further discussion in Sect. 7.

\section{The community earth system model}

The model used in this study is the Community Earth System Model (CESM), supported by the National Center for Atmospheric Research (NCAR). The CESM, superseding its previous version of the Community Climate System Model (CCSM4), is a fully-coupled ESM that includes ocean, atmosphere, land, sea ice, and land ice components, interacting together through a central flux coupler, which can provide state-of-the-art simulations of the Earth's past, present and future climate states. The CESM uses one of three alternatives as its atmospheric component: either the Community Atmosphere Model (CAM), the high-top atmosphere Whole Atmosphere Community Climate Model (WACCM), or the CAM with chemistry (CAM-CHEM) model. The Community Atmosphere Model version 4 (CAM4), used in this study, has a finitevolume (FV) dynamical core with 26 vertical layers. The horizontal resolution is $0.9^{\circ}$ (longitude) $\times 1.25^{\circ}$ (latitude) upon the regular longitude-latitude grid. The model configuration is described in detail in Neale et al. (2012). The ocean component is based on the Parallel Ocean Program version 2 (POP2) of the Los Alamos National Laboratory, which has 60 vertical levels varying from $10 \mathrm{~m}$ below the surface to a depth of $250 \mathrm{~m}$. It uses spherical coordinates in the Southern Hemisphere, and a displaced pole grid in the Northern Hemisphere. The horizontal resolution is approximately $1^{\circ}$ (longitude) $\times 0.27^{\circ}$ (latitude) at the equator, with the domain ranging from $79^{\circ} \mathrm{S}$ to $89^{\circ} \mathrm{N}$. Further details on the ocean component can be found in Smith et al. (2010). The CAM4 and POP2 are coupled through the version 7 coupler (CPL7) (Craig et al. 2012) together with the Community Land Model version 4.0 (CLM4) (Oleson et al. 2010), the Los Alamos sea ice model, referred to as the Community Ice CodE version 4.0 (CICE4) (Hunke and Lipscomb 2008), and a dynamic ice sheet model known as Glimmer-CISM (Rutt et al. 2009; Lipscomb et al. 2013). More details of the CESM model configuration and its simulation of the climate system are given in Hurrell et al. (2013). The model demonstrates some biases in the tropical Pacific interannual variability, such as a westward displacement (compared to observations) of the location of maximum warming (Capotondi 2013) and an underestimation of ENSO asymmetry (Zhang and Sun 2014). However, the fundamental characteristics of modeled El Niño generally compare well with observations (Bellenger et al. 2014).

\section{Experimental strategy}

To study the initial error that causes a significant SPB for an El Niño event, we conduct perfect model experiments in this study. That is to say, the CESM is assumed to be perfect and the prediction uncertainties of El Niño events are considered to be caused only by initial errors. We integrate the CESM model for 150 years with forcings of tracer gases, insolation, aerosols and land cover during the year 2000, and yield a control run. Taking the last 100 years of the simulation so as to eliminate initial adjustment processes, it is found that the control run reproduces reasonably the fundamental characteristics of the tropical Pacific. Figure 1 shows the winter mean SST climatology and standard deviation of the simulated interannual SST anomalies in November-January (NDJ), at the peak phase of El Niño events. The simulated climatological SST and interannual variability are comparable to those in observation except that the location of strong variability in the CESM shifts slightly westward than observed, which is a common symptom in the current coupled global climate models (CGCMs) (AchutaRao and Sperber 2002). The standard deviation of Niño-3 index (averaged SSTA in $5^{\circ} \mathrm{S}-5^{\circ} \mathrm{N}$, $150^{\circ}-90^{\circ} \mathrm{W}$ ) at each calendar month is also presented in Fig. 1. Compared to observation, the minimum variance of simulated Niño-3 SST anomalies appears about 1 month later than the observed, and the variance is rather flat in the boreal autumn and winter. This indicates that the El Niño events generated by the CESM model may peak in late autumn or winter, being somewhat earlier than observed El Niño events. This may be related to the simulated climatological annual cycle (Fig. 1a3). In any case, the mean 
Fig. 1 a Climatology of SSTs $\left({ }^{\circ} \mathrm{C}\right)$ over the tropical Pacific during $\mathrm{ND}(0) \mathrm{J}(1)$ from a1 the CESM and $\mathbf{a} 2$ the monthly Extended Reconstructed Sea Surface Temperature Version 3 (ERSST V3) dataset of the period 1952-2011. The thick black lines in (a1) and (a2) indicate the $28{ }^{\circ} \mathrm{C}$ isotherm. $\mathbf{a 3}$ The climatological SSTs averaged in Niño-3 region at each calendar month from CESM and ERSST. b Same as a but for the standard deviation of SST anomalies $\left({ }^{\circ} \mathrm{C}\right)$ (a) Climatology

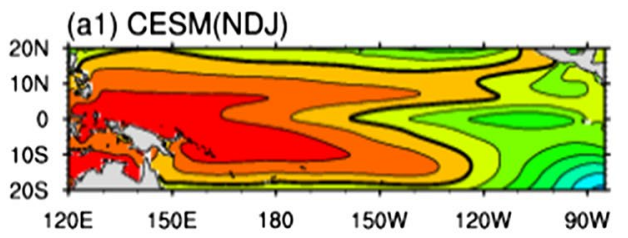

(a2) ERSST(NDJ)

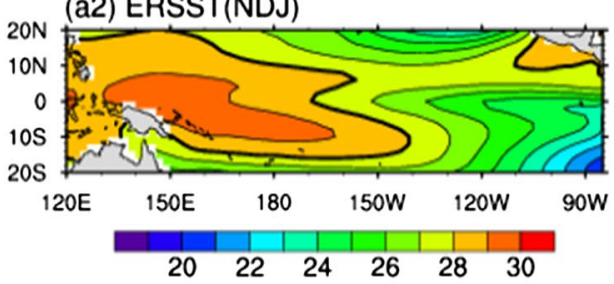

(a3) Nino3 region

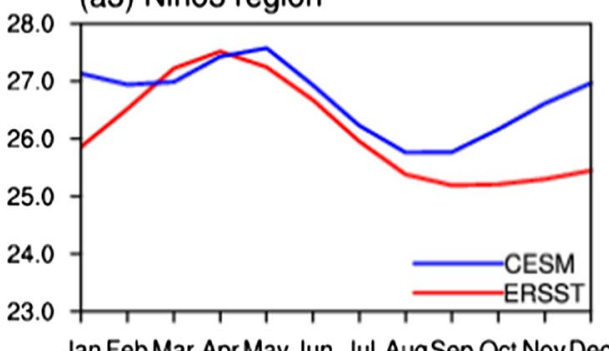

Jan Feb Mar Apr May Jun Jul AugSep Oct Nov Dec (b) STD

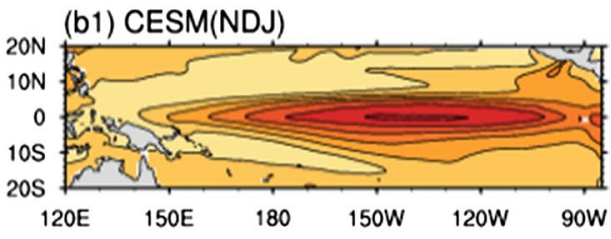

(b2) ERSST(NDJ)

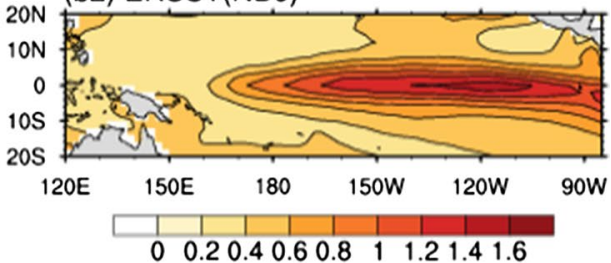

(b3) Nino3 region

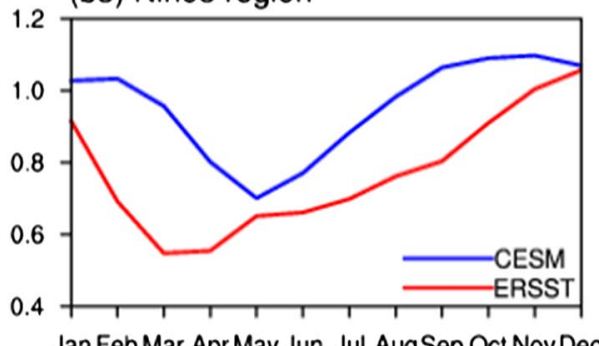

Jan Feb Mar Apr May Jun Jul AugSep Oct NovDec
Fig. 2 Lagged autocorrelation coefficients of monthly anomalies for a Niño-3 SST and $\mathbf{b}$ WWV [determined by spatial integration of the depth of the $20^{\circ} \mathrm{C}$ isotherm, Z20, over the region $\left(5^{\circ} \mathrm{S}-5^{\circ} \mathrm{N}\right.$, $120^{\circ} \mathrm{E}-80^{\circ} \mathrm{W}$ ), as in Mcphaden (20003)] as a function of the starting calendar month and lag time. The calculations are made for the last 100 years of the 150 year control simulation in the CESM model. The characteristics of the spring persistence barrier are consistent with those shown in observations reported by Yu and Kao (2007) (a) NINO3

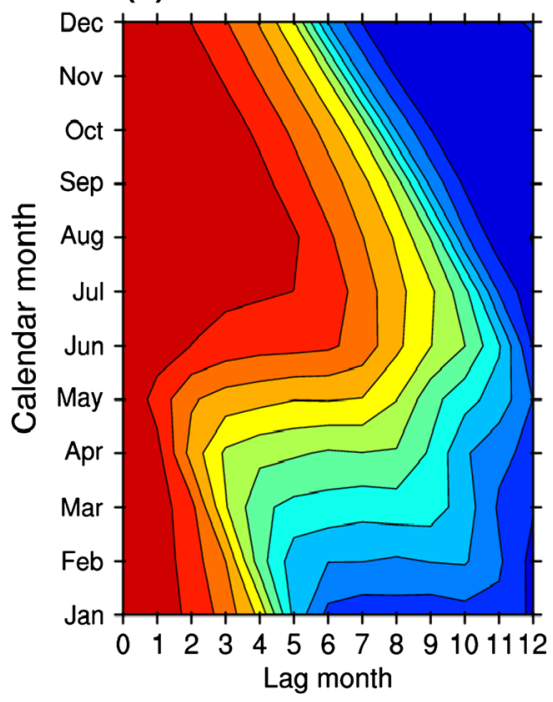

(b) WWV

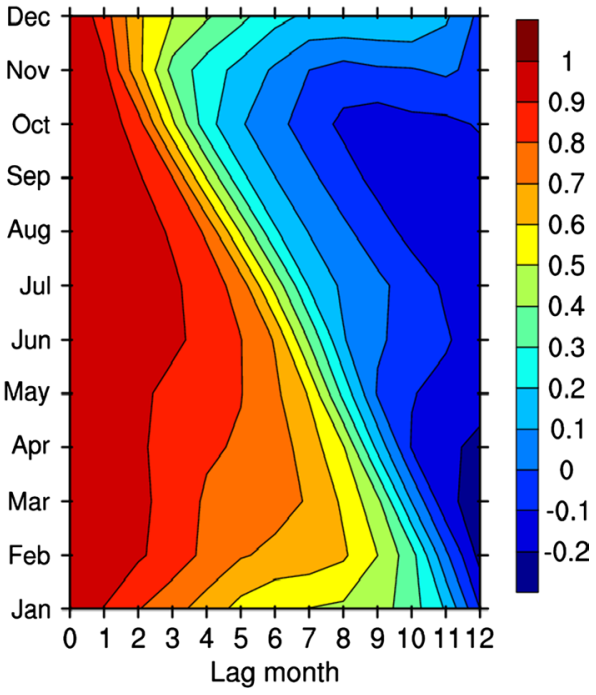

seasonal variance of Niño-3 SSTA in the CESM still tends to have weak ones in boreal spring, suggesting a relatively feasible climatological annual cycle. The control run also show irregular occurrence of El Niño events with a dominant period of 3 years. Especially, the CESM can capture the observed spring persistence barrier of Niño-3 index (Fig. 2a), which exhibits a rapid drop in the auto-lag correlation of Niño-3 index occurring in boreal spring. Moreover, the relationship between ENSO SSTA and WWV anomalies, as well as the winter persistence barrier of WWV anomalies, can be reproduced (Fig. 2b). As such, the CESM is deemed acceptable for investigating the SPB for El Niño events. Since the model is assumed to be perfect, the El Niño events generated by the model's control run are regarded as the "true state" El Niño events to be predicted. It should be noting that the El Niño events generated by the CESM's control run are often strong, which could be due to the effect of the forcing used in the integrated simulation. 
Therefore, in this paper we have to focus on these relatively strong model El Niño events.

Samelson and Tziperman (2001) argued that the inherent predictability of ENSO varies throughout the ENSO cycle, with the lowest predictability during the growth phase, and the SPB may be a manifestation of the growth phase barrier. In this study, we therefore focus on the predictability of the onset of El Niño events, paying particular attention to the predictions bestriding spring during the growth phase of El Niño events, in an attempt to investigate the SPB phenomenon. We select typical El Niño events from the control simulation. The so-called typical El Niño events tend to onset in boreal spring and peak in late autumn or winter. As such, there obtain six typical El Niño events. Figure 3 shows the time-dependent Niño-3 indices for the six El Niño events, which are denoted as $\mathrm{SR}_{\mathrm{i}}(\mathrm{i}=1, \ldots, 6)$. In this context, we use $\operatorname{Year}(0)$ to denote the year when El Niño

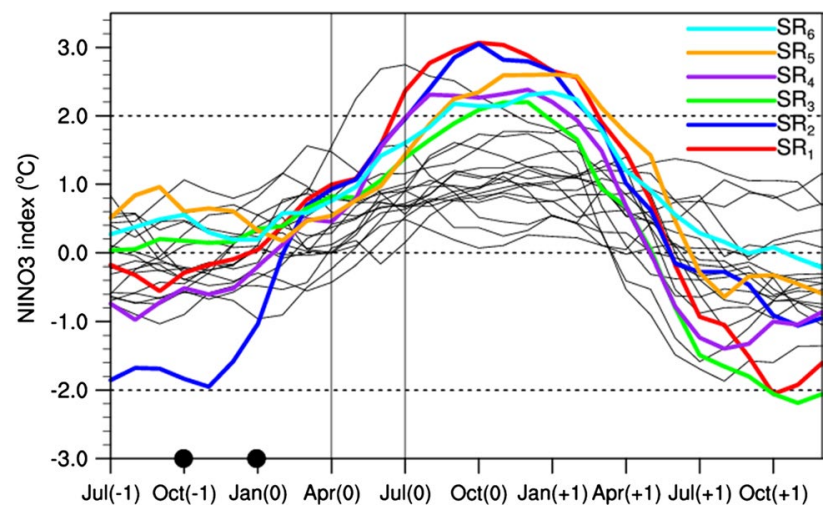

Fig. 3 Time-dependent Niño-3 indices of El Niño events from the 100 years control run of the CESM model. Colored curves indicate the six "true state" El Niño events, denoted by $\mathrm{SR}_{\mathrm{i}}(\mathrm{i}=1, \ldots, 6)$, which are chosen to conduct the perfect model predictability experiments. The start months of predictions for these El Niño events are marked on the horizontal axis, where the black bullet points denote the start months of October $(-1)$ and January $(0)$

attains a peak value and Year $(-1)$ to signify the year before Year(0). For each El Niño event, we make 12-month predictions (i.e. lead time of 12 months), with the start months being October $(-1)$ and January(0), respectively. These predictions are made through spring in the growth phase of $\mathrm{El}$ Niño. As mentioned above, we focus on the predictions of the onset of El Niño events.

The initial errors are superimposed on the initial sea temperature fields of the six "true state" El Niño events. Considering that the dominant period of El Niño is about 3 years, the initial errors are generated by taking the differences between the sea temperature of the "true state" El Niño events at the start month, and that in each month of the 3 years preceding each El Niño year, which may be responsible for much ergodic initial errors. For example, when the start month is October(-1), the first initial error is determined by subtracting the sea temperature of October $(-1)$ from that of September $(-1)$; when September $(-1)$ is changed to August $(-1)$, the sea temperature difference between these 2 months will be the second initial error, and so forth. Therefore, at each start month, we have 36 different initial error patterns to be superimposed on the initial values of each El Niño event. In total, there are 432 predictions for the two start months of the six El Niño events. Several studies have used the ZC model to examine the initial errors that cause a significant SPB for El Niño (Mu et al. 2007b; Duan et al. 2009; Yu et al. 2009). However, the ZC model is a simple model and cannot depict the evolution of subsurface temperature anomalies, which are important for the onset of El Niño events. In this study, we adopt the CESM, which is a complex earth system model and can explore the role of subsurface temperature anomalies in the occurrence of an SPB. In the numerical experiments, the initial errors of the sea temperature fields cover the region $\left(20.19^{\circ} \mathrm{S}-20.05^{\circ} \mathrm{N}, 130.44^{\circ} \mathrm{E}-84.49^{\circ} \mathrm{W}\right)$; and to explore the role of subsurface processes, the initial errors extend from the surface to $165 \mathrm{~m}$ depth, which is approximately the bottom of the thermocline over the western equatorial Pacific. Quite a few studies emphasized the importance of the spatial structure of initial errors in yielding SPB (Xue et al. 1994; Duan et al. 2009; Yu et al. 2012); furthermore, we found that the initial errors being normalized often cause an initial shock phenomenon that characterized as a rapid growth of errors within a short time after the beginning of predictions, which may be due to the dynamical unbalance among different levels of the upper ocean temperature field induced by normalized initial errors. It is therefore pointed out that the magnitudes of the initial errors are not constrained uniformly in numerical experiments and the spatial pattern of initial errors is mainly emphasized.

To study the evolution of initial errors, the prediction errors are defined as the difference between the SSTA in the Niño-3 region (Niño-3 SSTA) of the predicted El Niño and those of the "true state" El Niño events, which are expressed as follows:

$T^{\prime}(t)=\left\|T^{p}(t)-T^{t}(t)\right\|=\sqrt{\frac{\sum_{i, j}\left[T_{i, j}^{p}(t)-T_{i, j}^{t}(t)\right]^{2}}{N}}$,

where the prediction error $T^{\prime}(t)$ is measured by the norm $\|\cdot\|$ shown in Eq. (3.1), $T^{p}$ represents the predicted SSTA, $T^{t}$ is the "true state" SSTA, $(i, j)$ are the grid points in the Niño-3 region, and $\mathrm{N}$ is the total grid number of the Niño-3 region. In prefect model predictability experiments, the prediction error is only caused by the growth of initial errors. To explore the season-dependent evolution of prediction errors, we divide a calendar year into four seasons, starting with January to 
Fig. 4 Upper panels show the evolution of prediction errors of Niño-3 SSTA caused by each SPB-related initial error (colored curves) and the ensemble mean of seasonal growth rate $\kappa$ (histograms) of the SPBrelated initial errors. Lower panels show the corresponding prediction errors of Niño-3 index (colored curves) and their ensemble mean (thick black lines). The start months of the predictions are a October $(-1)$ and b January(0) (a) Oct(-1)
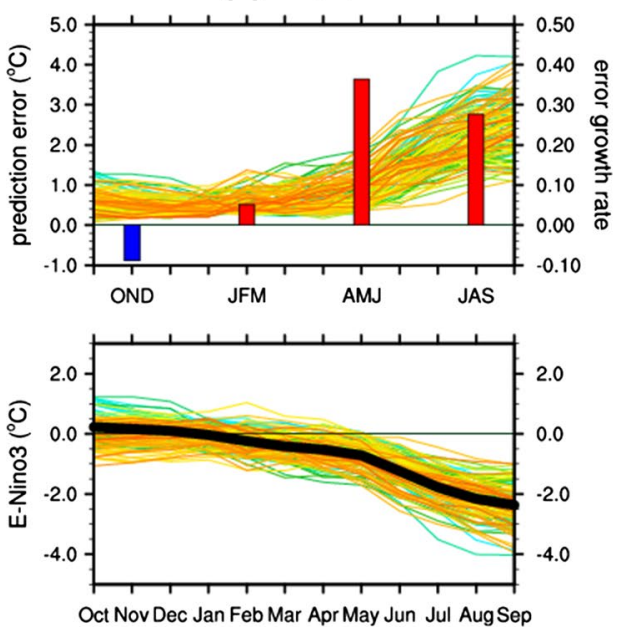

(b) $\operatorname{Jan}(0)$
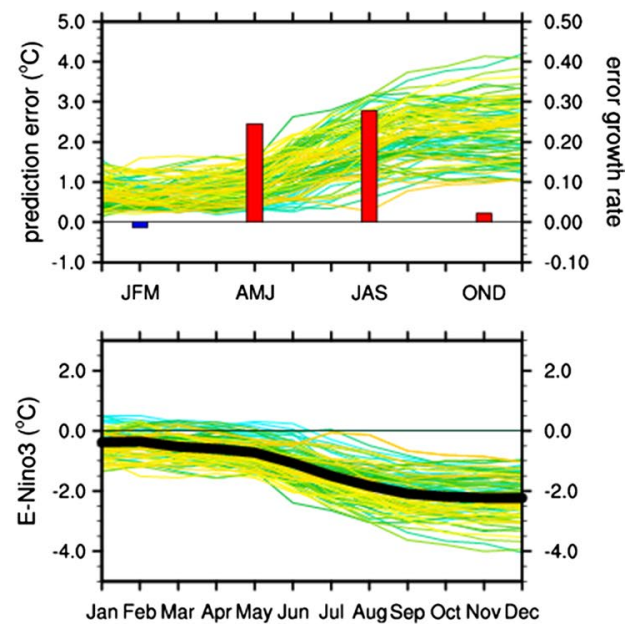

March (JFM), followed by April to June (AMJ), and so forth. Then, the growth tendency $\kappa$ of prediction errors in different seasons can be roughly estimated by evaluating

$\kappa \approx \frac{T^{\prime}\left(t_{2}\right)-T^{\prime}\left(t_{1}\right)}{t_{2}-t_{1}}$,

where $T^{\prime}\left(t_{1}\right)$ represents the prediction error at the start time of a season, $T^{\prime}\left(t_{2}\right)$ is at the end of the season, and $t_{2}-t_{1}$ is the time interval length. A positive (negative) value of $\kappa$ corresponds to an increase (decrease) of errors, and the larger the absolute value of $\kappa$, the faster the increase (decrease) of errors.

\section{Two types of initial errors that often cause the SPB for El Niño events}

A significant SPB, as stated earlier, involves two aspects: a large prediction error at the end of the prediction period, and an obvious error growth occurring during boreal spring. Based on this definition of the SPB and the experimental strategy described above, from the 432 predictions for the six El Niño events, we identify 212 predictions [ 120 for the start month October $(-1)$ and 92 for January $(0)]$ that yield a significant SPB. Obviously, the SPB of these predictions for the tropical SSTA associated with El Niño is induced by initial errors. For convenience, we refer to these initial errors as "SPB-related initial errors". To illustrate the SPB phenomenon clearly, we present in Fig. 4 the evolution of the prediction errors of Niño-3 SSTA [see Eq. (3.1)] and the ensemble mean of their seasonal growth tendency $\kappa$ [see Eq. (3.2)] corresponding to the SPB-related initial errors. It is illustrated that the SPB-related initial errors exhibit significant season-dependent evolution for both start months (see the upper panel in Fig. 4). For the errors with the start month of October $(-1)$, their largest growth tendency tends to be in the AMJ season, which is consistent with the rapid decline in the spring forecast skill for El Niño in most prediction schemes (Latif et al. 1998; Webster and Yang 1992), indicating occurrence of an SPB; while the errors with the start month of January(0) are inclined to have considerable growth in both AMJ and JAS, with the largest growth in JAS. For the latter, Mu et al. (2007b) argued that although the largest growth of the initial errors occurs in the JAS season, the error growth during AMJ has become aggressively large and may cause the drastic decrease in $\mathrm{El}$ Niño forecast skill across the spring, and also induce the SPB phenomenon. To further investigate the uncertainties caused by the SPB-related initial errors of El Niño prediction with 1-year lead time, we also determine the prediction errors of Niño-3 index, denoted as "E-Niño3", by subtracting the Niño-3 indices of the "true state" El Niño events from the predicted ones (see the lower panel of Fig. 4). A positive (negative) value of E-Niño3 shows a positive (negative) prediction error in Niño-3 SSTA and indicates an over-prediction (under-prediction) of the El Niño event. The values of E-Niño3 shown in Fig. 4 demonstrate that the SPB-related initial errors usually cause large uncertainties of Niño-3 SSTA at the end of the prediction period. Also, we can see that all the SPB-related initial errors yield a negative error of Niño-3 SSTA and induce an under-prediction of the corresponding El Niño events. Nevertheless, from Fig. 4 we notice that the Niño-3 index amplitudes of some initial errors are larger than $0.5{ }^{\circ} \mathrm{C}$ and are not comparable to the realistic initial SSTA errors. Therefore, we further select the SPB-related initial errors with Niño-3 index amplitudes less than $0.5^{\circ} \mathrm{C}$ from those in Fig. 4 and plot their evolutions in Fig. 5. The results still show the season-dependent evolution of prediction errors caused by these initial errors, with the significant error growth in AMJ and/or JAS, indicating occurrence of a significant SPB for El Niño events as well. 
Fig. 5 As in Fig. 4, but for the SPB-related initial errors with the Niño-3 index amplitude less than $0.5^{\circ} \mathrm{C}$ (a) Oct(-1)
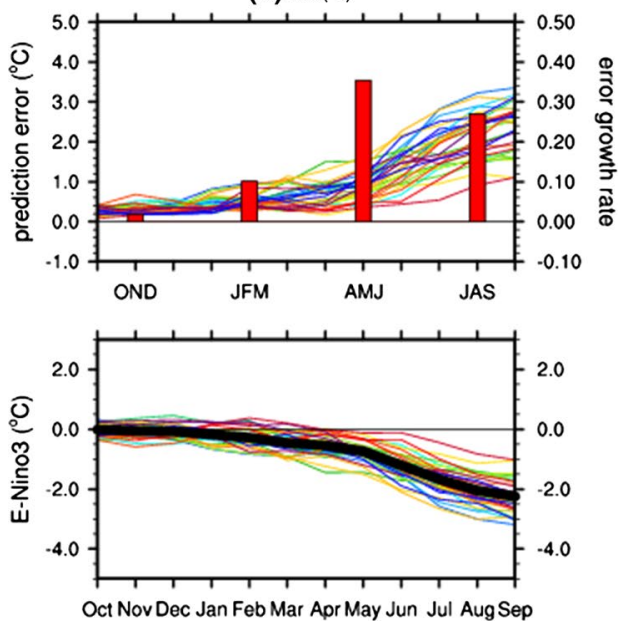

(b) $\operatorname{Jan}(0)$
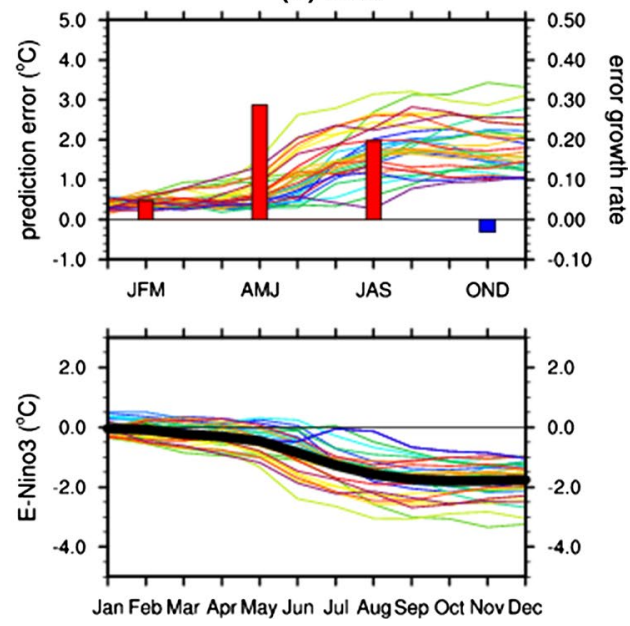

(a) type-1 error
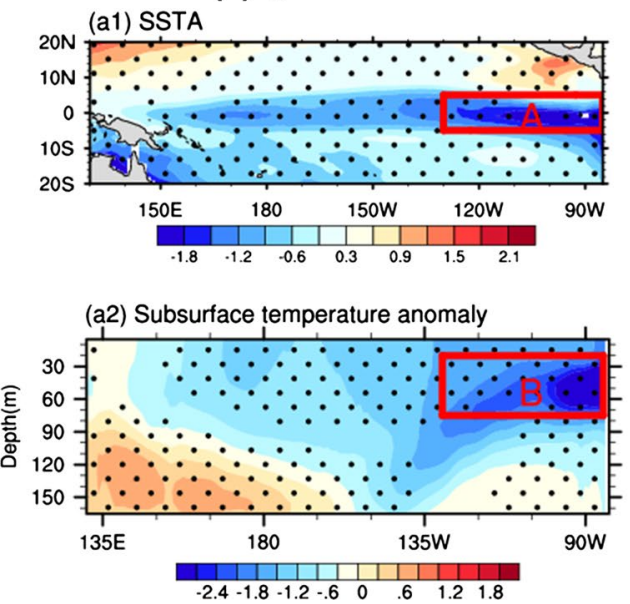

(b) type-2 error
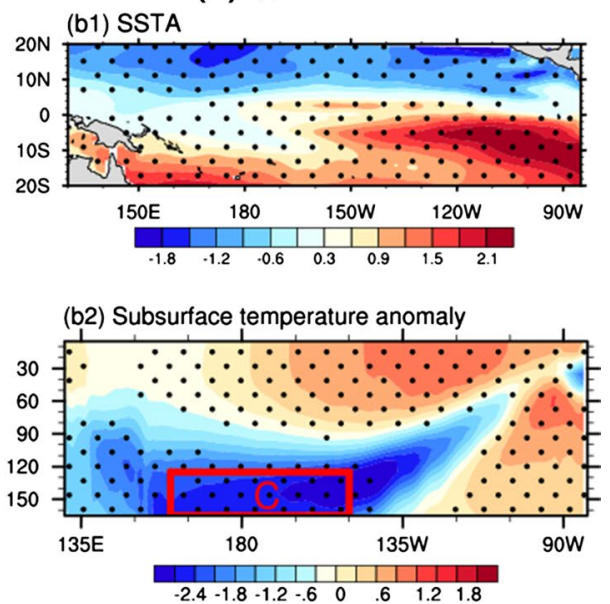

$\left.150^{\circ}-85^{\circ} \mathrm{W} ; 5-85 \mathrm{~m}\right)$ and $\left(5^{\circ} \mathrm{S}-5^{\circ} \mathrm{N}, 150^{\circ} \mathrm{E}-135^{\circ} \mathrm{W} ; 120-165 \mathrm{~m}\right)$, respectively. Dotted areas indicate that the composites of SSTA and subsurface temperature anomaly errors exceed the $99 \%$ significance level, as determined by a $t$ test

phase but also a negative phase, which means that the dominant mode of the initial errors could be either the CEOF1 pattern or its opposite pattern. Following this, we classify the 212 initial errors into two groups, with 101 in one group corresponding to positive $\mathrm{PC} 1$, and 111 in the other group possessing negative PC1. That is, the SPB-related initial errors are classified into two groups according to the PC1's sign. It should be noted that, classification is operated on those original SPB-related initial errors rather than the CEOF1 mode. Then through composite analysis for the two groups of initial errors, we obtain two types of composite patterns of the SSTA and subsurface temperature anomaly along the equatorial Pacific (Fig. 6). It is shown that one type of initial errors possesses an SSTA pattern indicate that the CEOF1 mode exhibits not only a positive 
with negative anomalies over the central-eastern equatorial Pacific, plus a basin-wide dipolar pattern in the subsurface temperature anomaly with negative anomalies in the upper layers of the eastern equatorial Pacific and positive anomalies in the lower layers of the central-western equatorial Pacific (Fig. 6a; hereafter referred to as type-1 initial errors). As for the other type of initial errors, it consists of an SSTA component with positive anomalies that are more confined over the southeastern equatorial Pacific. Also, there is a large-scale zonal dipole pattern of the subsurface temperature anomaly, with positive anomalies in the upper layers of the eastern equatorial Pacific and negative anomalies in the lower layers of the western equatorial Pacific, but its negative pole is located in the central Pacific (Fig. 6b; hereafter referred to as type- 2 initial errors). For the type- 1 and -2 initial errors, we also compute the similarity coefficients between their composite patterns and corresponding two groups of individual initial errors and show high similarities between them; exactly, the mean of similarity coefficients reach about 0.6 for type- 1 errors and 0.7 for type- 2 errors. The above classification is also supported by a cluster analysis with similarity coefficient as a measurement (not shown). Therefore, it is reasonable to suggest that the type- 1 and -2 initial errors could illustrate the dominant characteristics of initial errors that often cause a significant SPB of El Niño prediction in the CESM model. As for the initial errors that fail to cause an SPB, we fail to obtain their dominant spatial structure with large explained variance in numerical experiments. This indicates that the initial errors that fail to cause a significant SPB do not present a uniform spatial structure. As a comparison, the dominant characteristics of the SPB-related initial errors may emphasize the importance of the initial errors with a particular spatial structure in yielding SPB for El Niño events.

\section{Dynamical mechanisms of error growth related to the SPB for El Niño events}

Having demonstrated in Sect. 4 the existence of two types of initial errors that often cause predictions of El Niño onset to yield a significant SPB in the CESM model, and that these errors induce a large prediction error for Niño-3 SSTA (specifically, both error types cause El Niño events to be under-predicted), we therefore naturally ask: why do the errors cause a negative prediction error of Niño-3 SSTA for El Niño events? That is to say, what is the dynamical mechanism underpinning the two types of SPB-related initial errors? Duan et al. (2009) and Yu et al. (2009) identified two initial errors of opposite sign that are most likely to evolve into El Niño-like and La Niña-like modes, respectively, in the ZC model (Zebiak and Cane 1987). We therefore also ask: is the behavior of the SPB-related error growth in the CESM similar to El Niño and La Niña events? To address these questions, we explore the timedependent evolution of the prediction errors caused by the two types of SPB-related initial errors.

We integrate the CESM model with the initial values being the initial sea temperature of each "true state" El Niño event plus the type- 1 and -2 initial errors; and then, by subtracting the "true state", obtain the evolution of the prediction errors caused by the two types of initial errors, respectively. By observing the patterns of prediction errors-including the SSTA, sea surface wind anomaly and equatorial subsurface temperature anomaly components-we find that the type-1 initial errors present a growth behavior with a La Niña-like evolving mode. In this case, the negative SST anomalies in the central-eastern equatorial Pacific in the initial errors are rapidly amplified during several months and evolve into a mature La Niña-like mode at the prediction time. Whereas, for the type-2 initial errors, they initially experience a period similar to an El Niño decaying phase, and subsequently exhibit a transition to a cold phase, finally evolving into a mature La Niña-like mode. Figures 7 and 8 show a composite of the evolution of the prediction errors caused by the two types of SPB-related initial errors, and present the major mode of their evolutions. The results illustrate that the two types of errors exhibit a growth behavior similar to a La Niña event, but they may start from a different phase of the La Niña evolving mode. The type-1 initial errors start directly from the growth phase of La Niña due to positive feedback, while the type- 2 initial errors develop including the decaying phase of El Niño through negative feedback, and then transition to a development of La Niña through positive feedback.

Physically, when the type-1 initial errors are superposed on the initial state of an El Niño event, a large negative SSTA error initially occurs in the central-eastern equatorial Pacific and a much weaker positive subsurface temperature anomaly is located in the greater depths of the western equatorial Pacific (see the top panel of Fig. 9). On the one hand, the large negative SSTA leads to anomalous easterlies along the equator, such that Bjerknes positive feedback (Bjerknes 1969) develops over the eastern equatorial Pacific, and meanwhile the associated larger negative subsurface temperature anomalies beneath are transported upward by upwelling until they reach the surface, which is consistent with the "upwelling pathway" between Z20 (i.e. the depth of the $20^{\circ} \mathrm{C}$ isotherm) and SST suggested in Zelle et al. (2004). Both contribute to the sustained growth of the negative SSTA errors over the eastern equatorial Pacific. On the other hand, the weaker positive subsurface temperature anomalies in the western equatorial Pacific lower the depth of the thermocline and induce a downwelling Kelvin wave that travels from the western equatorial Pacific to the eastern Pacific, where it causes a positive SSTA and hence causes the initial negative SSTA errors to 
(a) SSTA+Wind anomaly
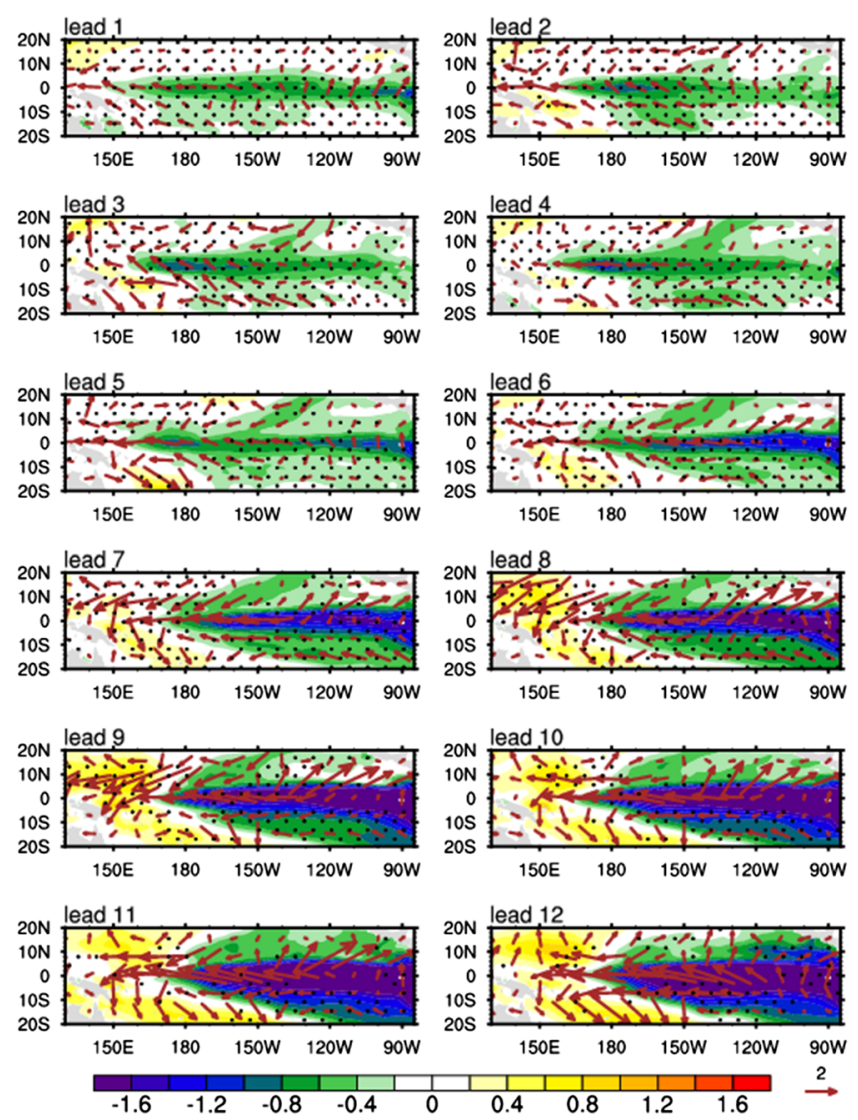

Fig. 7 Composite evolutions of type-1 initial errors: a SSTA (units: ${ }^{\circ} \mathrm{C}$ ) and sea surface wind anomaly (units: $\mathrm{m} / \mathrm{s}$ ) over the tropical Pacific Ocean; b equatorial $\left(5^{\circ} \mathrm{S}-5^{\circ} \mathrm{N}\right)$ subsurface temperature

weaken. This remote interaction between wave dynamics and SSTAs competes with the Bjerknes positive feedback as well as the local "upwelling pathway" over the eastern equatorial Pacific. Whether or not the negative SSTA error will be amplified depends on the relative importance of the two competing mechanisms. During the earlier evolution of the type- 1 errors, these two competing influences almost offset each other, and the negative SSTA errors remain, showing no significant growth. However, because of the weakness of the initial positive subsurface temperature anomalies in the western Pacific, the negative feedback associated with the wave dynamics decays gradually and disappears after several months. Afterwards, therefore, the positive feedback mechanism plays a dominant role and causes the negative SSTA errors to be further amplified, ultimately evolving into a La Niña mode and yielding negative prediction errors for the El Niño events.

For the type-2 initial errors, the initial positive SSTA error is confined to the southeast of the equatorial Pacific, where a weak westerly anomaly occurs only over the central tropical Pacific (Fig. 9a2, b2), and consequently the (b) Subsurface temperature anomaly
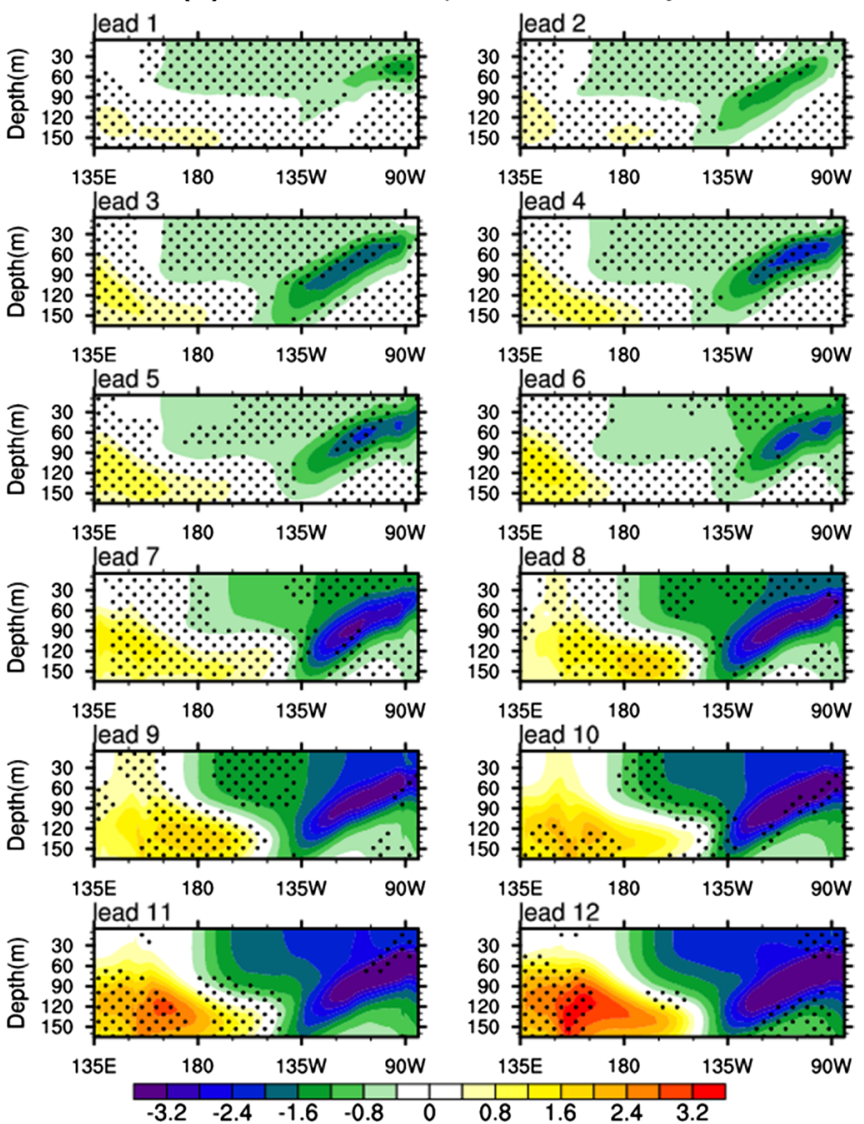

anomaly (units: ${ }^{\circ} \mathrm{C}$ ). Dotted areas indicate the composites of SSTA and subsurface temperature anomaly errors pass the $95 \%$ significance level, as determined by a $t$ test

Bjerknes feedback process fails to establish. However, the large negative subsurface temperature anomalies lift the thermocline of the western equatorial Pacific (Fig. 9c2) and generate upwelling Kelvin waves that propagate eastward, carrying cold water with them and causing a negative SSTA in the eastern Pacific. The negative SSTA will then induce zonal easterly wind anomalies in the central Pacific, leading to the warm SSTA error and westerly anomalies to decay and disappear gradually (Fig. 9a2, b2). Once the warm SSTA error disappears and the negative SSTA error subsequently occurs over the eastern equatorial Pacific, the cooling error will be further intensified through the easterlies and anomalous upwelling due to the Bjerknes positive feedback mechanism, also underestimating the El Niño events. In short, for the earlier development of the type- 2 errors, the negative feedback associated with equatorial waves travelling from the western equatorial Pacific has a first-order effect; while once a negative SST anomaly over the eastern equatorial Pacific occurs, the Bjerknes positive feedback becomes the leading factor. 
(a) SSTA+Wind anomaly
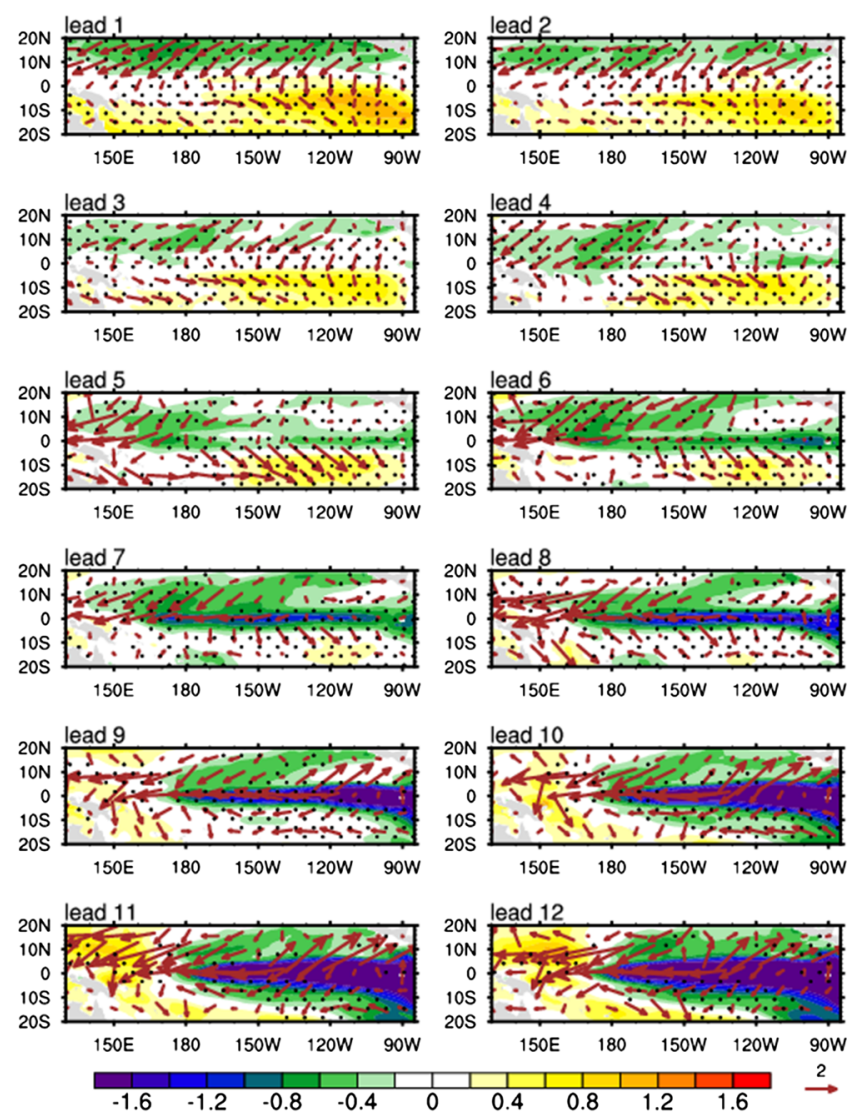

Fig. 8 As in Fig. 7, but for type-2 initial errors

\section{Implications}

The results thus far described have demonstrated that two types of SPB-related initial errors exist for El Niño events in the CESM model, and that they cause significantly large prediction errors (see Sect. 4). In particular, it is apparent that the negative prediction errors for Niño-3 SSTA caused by the type- 1 initial errors grow to be large in the eastern equatorial Pacific (see region A in Fig. 6), mainly due to the contribution of cold water from the subsurface layers of the eastern equatorial Pacific (see region B in Fig. 6). Therefore, if we reduce the initial errors in regions $\mathrm{A}$ and $B$, the resultant prediction errors for Niño-3 SSTA should be greatly decreased. For the type- 2 initial errors, the resultant negative prediction errors for Niño-3 SSTA first originate from the lower layers of the western equatorial Pacific (see region $\mathrm{C}$ in Fig. 6), and then grow to be large in the Niño-3 region. It is therefore reasonable to suggest that the El Niño predictions may also be sensitive to the initial errors of sea temperature in region C. Since the prediction errors for Niño-3 SSTA are sensitive to the initial errors (b) Subsurface temperature anomaly
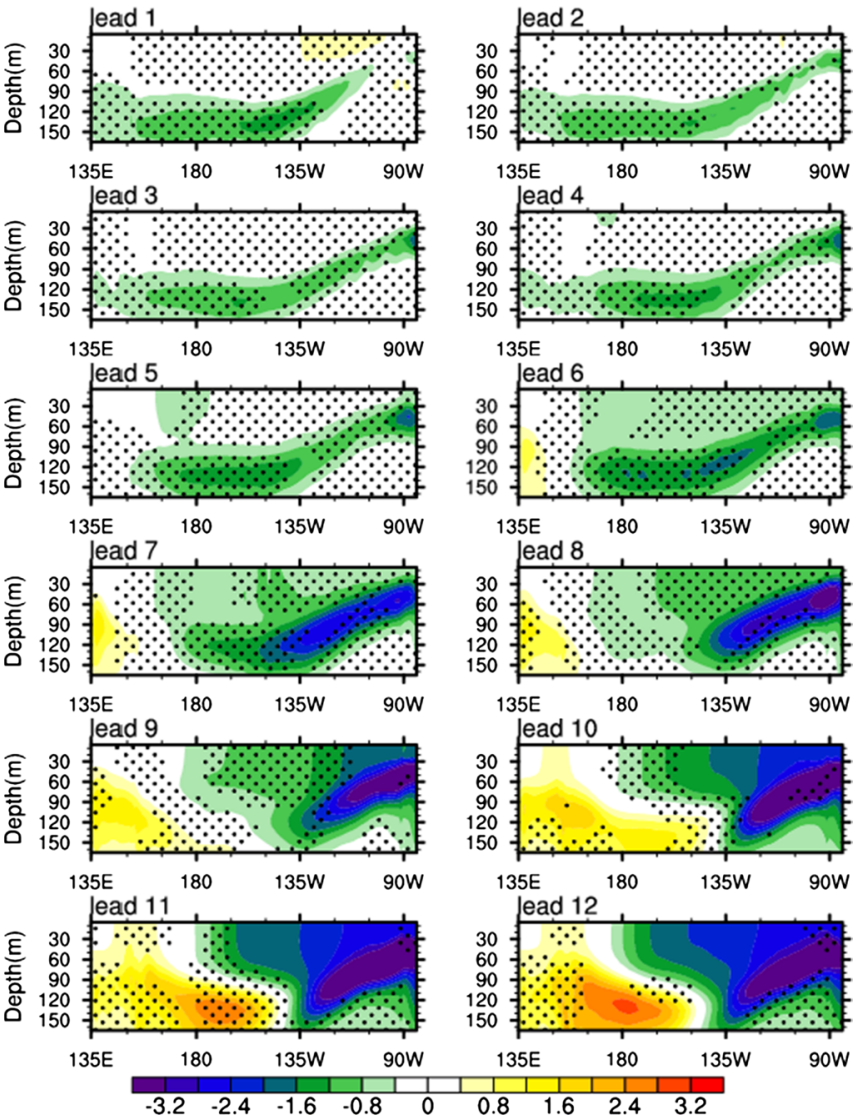
(a) taux at [5S-5N]
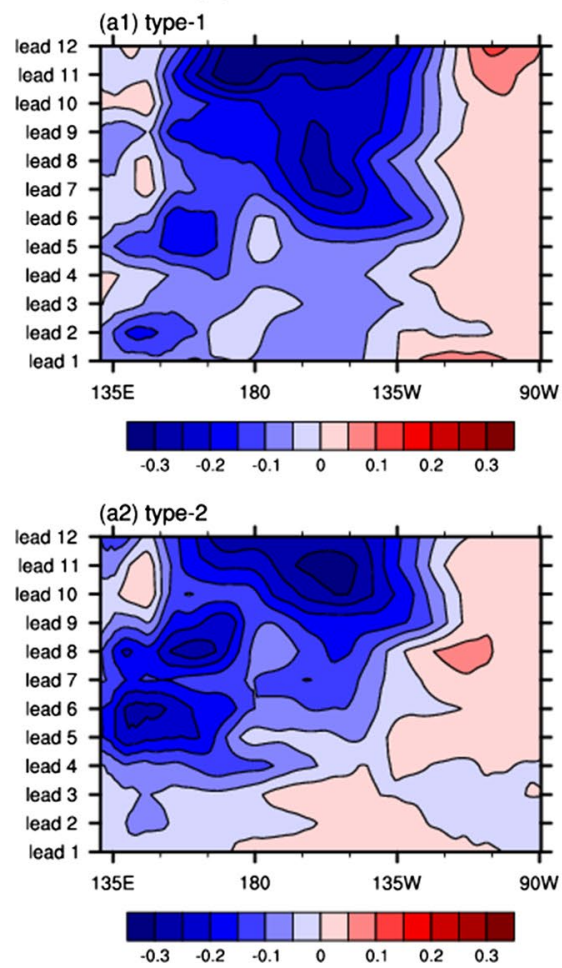

(b) SSTA at [5S-5N]
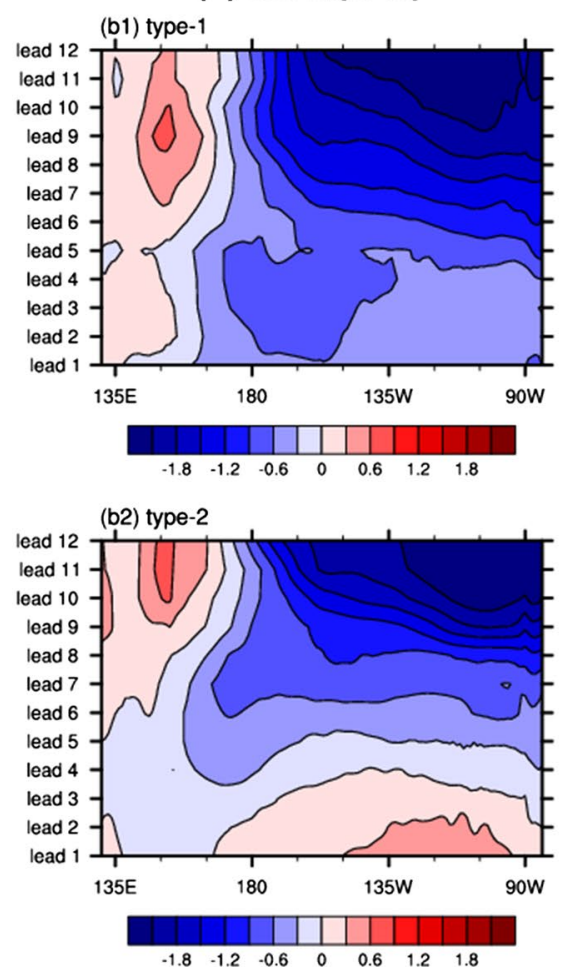

(c) $\mathrm{Z} 20$ at $[5 \mathrm{~S}-5 \mathrm{~N}]$

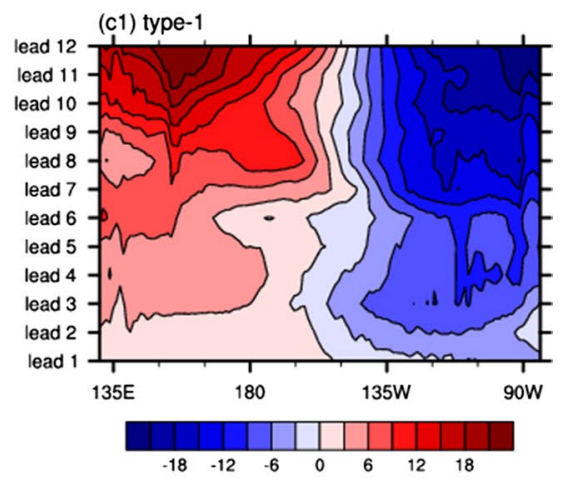

(c2) type-2

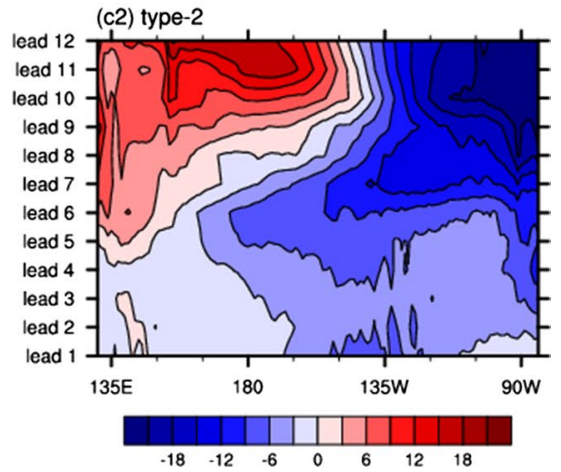

Fig. 9 Composite evolution of prediction errors for equatorial $\left(5^{\circ} \mathrm{S}-5^{\circ} \mathrm{N}\right)$ a zonal wind stress anomaly (units: dyn $\left./ \mathrm{cm}^{2}\right)$, b SSTA (units: ${ }^{\circ} \mathrm{C}$ ), and $\mathbf{c}$ thermocline depth anomaly (units: $\mathrm{m}$ ) over the tropical Pacific Ocean. The depth of the $20{ }^{\circ} \mathrm{C}$ isotherm is used here as a proxy for thermocline depth. Upper panels are for the type-1 initial errors; lower panels for type- 2 initial errors inferred that the above regions $\mathrm{A}, \mathrm{B}$, and $\mathrm{C}$ may represent the sensitive areas for El Niño predictions.

To illustrate this inference, we conduct additional numerical experiments for the type- 1 and -2 initial errors, respectively. Considering economy and efficiency of target observation, we define an index to measure the benefit of implementing target observation in regions $\mathrm{A}, \mathrm{B}$, and $\mathrm{C}$ in reducing prediction errors for El Niño.

Benefit $=\frac{\left(T_{\text {whole-region }}^{\prime}-T_{\text {non-sensitive-area }}^{\prime}\right) / T_{\text {whole-region }}^{\prime}}{V_{\text {non-sensitive-area }}}$ $\times 100 \%$,

where $T_{\text {whole-region }}^{\prime}$ represents the prediction errors caused by initial errors throughout the whole region of the tropical Pacific, $T_{\text {non-sensitive-area }}^{\prime}$ denotes the prediction errors caused by initial errors from non-sensitive areas, indicating initial errors in sensitive areas are eliminated by target observations, and $V_{\text {non-sensitive-area }}$ is the volume of related non-sensitive areas. The "Benefit" stands for the degree of reduction of the prediction errors after implementing target observations in per unit volume of sensitive areas. Compared this "Benefit" with that of implementing additional observations in per unit volume of non-sensitive areas (here is the outside regions of $\mathrm{A}, \mathrm{B}$, and $\mathrm{C}$ ), we can identify the region that is much economical and efficient for target observation, i.e. the sensitive area for targeting.

We adopt the strategy described in Sect. 3 to predict the six "true state" El Niño events for 1 year starting with October $(-1)$ and $\operatorname{January}(0)$, but instead separately add the type- 1 and -2 initial errors in Fig. 6 on the initial value of each "true state" El Niño, finally obtaining the prediction errors $T_{\text {whole-region }}^{\prime}$ caused by whole type- 1 and -2 initial errors, respectively. Figures 10 and 11 show the $T_{\text {whole-region }}^{\prime}$ of Niño-3 SSTA [measured by the norm described by Eq. (3.1); see the gray bars in the upper panel] and that of Niño-3 index (i.e. E-Niño3; see the gray bars in the lower panel) at the prediction time for each El Niño event. In the total of 24 predictions, 20 ones induce significantly large prediction errors, with its corresponding absolute value of E-Niño3 larger than $1.0^{\circ} \mathrm{C}$. Specifically, the type- 1 and -2 initial errors account for 10 predictions of 20 ones, respectively. Regarding to the prediction errors of Niño-3 SSTA measured by Eq. (3.1), the ensemble mean caused by the type- 1 initial errors is $2.43{ }^{\circ} \mathrm{C}$, and $2.14{ }^{\circ} \mathrm{C}$ for type- 2 initial errors. For these 20 predictions, the initial errors in regions $\mathrm{A}$ and $\mathrm{B}$ for type- 1 initial errors and region $\mathrm{C}$ for type- 2 are removed, 
(a) Oct(-1)
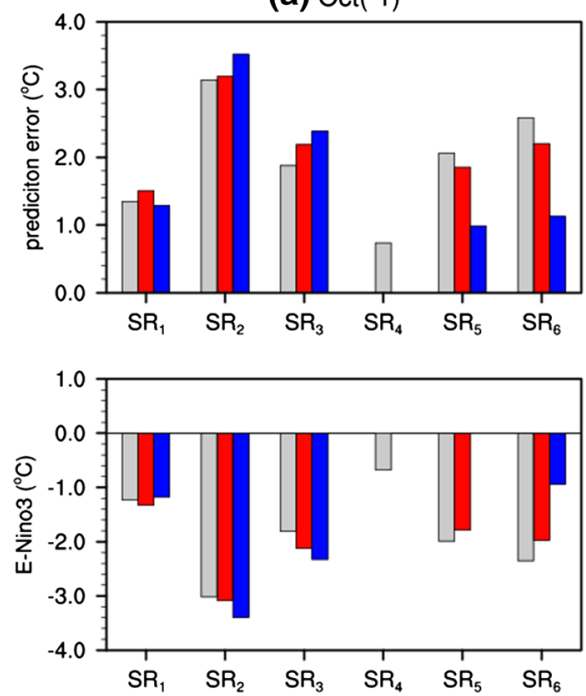

Fig. 10 Prediction errors of Niño-3 SSTA [measured by Eq. (3.1) in Sect. 3; upper panels] and its Niño-3 index component (i.e. E-Niño3) with 1-year lead time (lower panels) for six El Niño events [denoted as SRi $(i=1, \ldots, 6)$ ], caused by the type-1 initial errors (gray bars) and the initial error generated by keeping the initial sea temperature errors in regions $\mathrm{A}\left(10^{\circ} \mathrm{S}-10^{\circ} \mathrm{N}, 150^{\circ}-85^{\circ} \mathrm{W} ; 0-5 \mathrm{~m}\right)$ and $\mathrm{B}$ $\left(10^{\circ} \mathrm{S}-10^{\circ} \mathrm{N}, 150^{\circ}-85^{\circ} \mathrm{W} ; 5-85 \mathrm{~m}\right)$ (red bars) and eliminating errors in regions A and B from the type-1 initial errors (blue bars), respectively. The start months of predictions are $\mathbf{a} \operatorname{October}(-1)$ and $\mathbf{b}$ Janu-
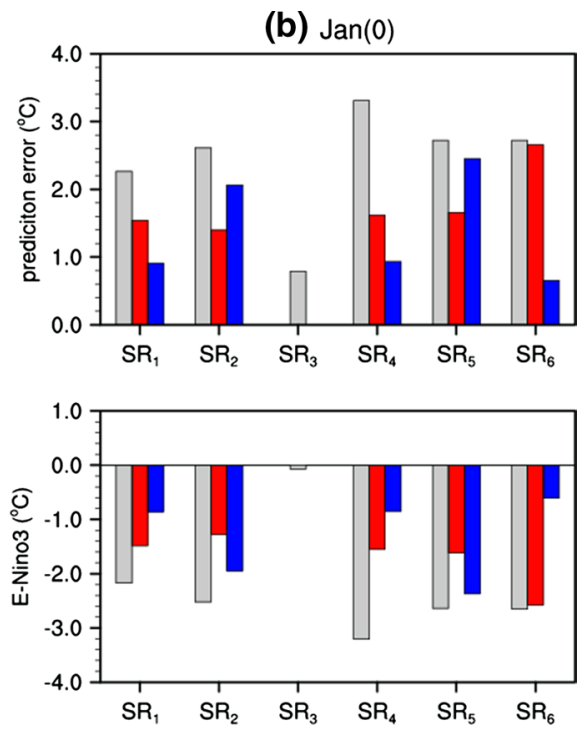

$\operatorname{ary}(0)$. There are 10 predictions with E-Niño3 larger than $1.0{ }^{\circ} \mathrm{C}$. For these 10 predictions, the ensemble mean of prediction errors of Niño3-SSTA caused by the type-1 initial errors is about $2.43{ }^{\circ} \mathrm{C}$. The ensemble mean is about $1.96{ }^{\circ} \mathrm{C}$ when only the initial errors in regions $\mathrm{A}$ and $\mathrm{B}$ are kept, which amounts to about $81 \%$ of the prediction errors caused by the type- 1 initial errors. The ensemble mean is about $1.61{ }^{\circ} \mathrm{C}$ when only the initial errors outside of regions $\mathrm{A}$ and $\mathrm{B}$ are kept, which amounts to about $66 \%$ (a) Oct(-1)
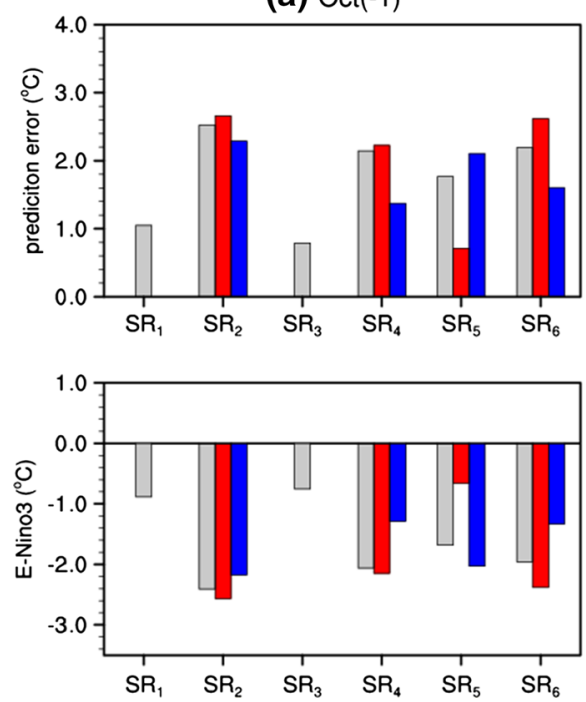

Fig. 11 As in Fig. 10, but for the type-2 initial errors (gray bars) and the initial error which is generated by keeping the initial sea temperature errors in region $\mathrm{C}\left(10^{\circ} \mathrm{S}-10^{\circ} \mathrm{N}, 150^{\circ} \mathrm{E}-135^{\circ} \mathrm{W} ; 95-165 \mathrm{~m}\right)$ (red bars) and eliminating errors in region $\mathrm{C}$ from the type- 2 initial errors (blue bars). There are 10 predictions with E-Niño3 larger than $1.0^{\circ} \mathrm{C}$. The ensemble mean of prediction errors of Niño3-SSTA caused by (b) $\operatorname{Jan}(0)$
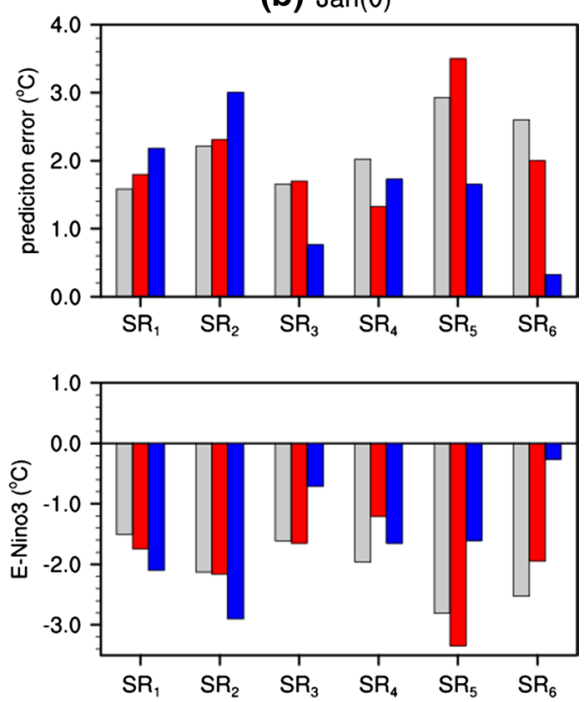

the type- 2 initial error is about $2.14{ }^{\circ} \mathrm{C}$. The ensemble mean is about $2.06{ }^{\circ} \mathrm{C}$ when only the initial errors in region $\mathrm{C}$ are kept, amounting to about $96 \%$ of the prediction errors caused by the type- 2 initial errors. The ensemble mean is about $1.68{ }^{\circ} \mathrm{C}$ when only the initial errors outside of region $\mathrm{C}$ are kept, amounting to about $79 \%$ 


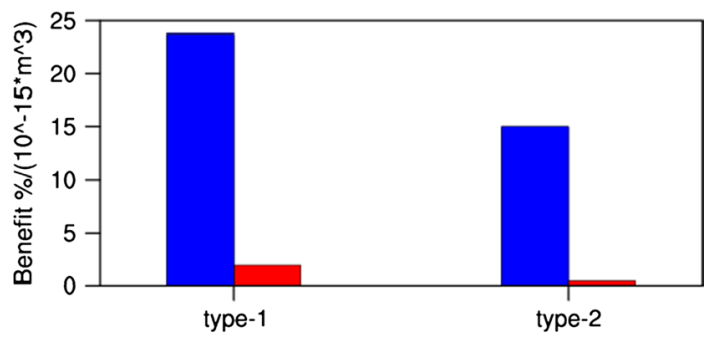

Fig. 12 Blue bars the benefit index obtained after performing target observations in the $\mathrm{A}\left(10^{\circ} \mathrm{S}-10^{\circ} \mathrm{N}, 150^{\circ}-85^{\circ} \mathrm{W} ; 0-5 \mathrm{~m}\right)$ and $\mathrm{B}$ $\left(10^{\circ} \mathrm{S}-10^{\circ} \mathrm{N}, 150^{\circ}-85^{\circ} \mathrm{W} ; 5-85 \mathrm{~m}\right)$ regions of type-1 initial errors and $\mathrm{C}\left(10^{\circ} \mathrm{S}-10^{\circ} \mathrm{N}, 150^{\circ} \mathrm{E}-135^{\circ} \mathrm{W} ; 95-165 \mathrm{~m}\right)$ of type- 2 initial errors. Red bars the benefit index for additional observations in those regions outside of A, B for type- 1 and those outside of $\mathrm{C}$ for type- 2 errors. The earth is seemed as a pure sphere with the radius of $6378 \mathrm{~km}$. The volume of the tropical Pacific $\left(20.19^{\circ} \mathrm{S}-20.05^{\circ} \mathrm{N}\right.$, $\left.130.44^{\circ} \mathrm{E}-84.49^{\circ} \mathrm{W} ; 0-165 \mathrm{~m}\right)$, approximated as a $3-\mathrm{D}$ rectangular region, is about $11.8 \times 1015 \mathrm{~m}^{3}$. The volume of $\mathrm{A}$ and $\mathrm{B}$ regions or $\mathrm{C}$ region, accounting for only $12 \%$, is about $1.42 \times 1015 \mathrm{~m}^{3}$, while those outside regions are about $10.4 \times 1015 \mathrm{~m}^{3}$

but the errors in other regions are retained, which can be understood as that the elimination of initial errors in A, $\mathrm{B}$, and $\mathrm{C}$ is due to the implementation of target observation in these regions. The resultant prediction error just is the one denoted by $T_{\text {non-sensitive-area. It shows that }}^{\prime}$ the resultant prediction errors of Niño-3 SSTA for most predictions account for about $66 \%$ of that caused by the whole type- 1 initial errors, and $79 \%$ of the whole type-2 initial errors (see blue bars in Figs. 10, 11). If we use the "Benefit" index to measure the degree of reduction of prediction errors, the results show that the prediction errors caused by the whole type- 1 and -2 initial errors are significantly reduced when implementing target observations in per unit volume of regions A, B for type-1 errors and $\mathrm{C}$ for type-2 errors (see Fig. 12). Exactly, the prediction errors are reduced by $23.8 \%$ for type- 1 errors and $15.0 \%$ for type- 2 errors. However, when we retain initial errors in regions A, B for type-1 and region $\mathrm{C}$ for type- 2 but eliminating initial errors in other regions, the subsequent prediction errors can only be reduced about $1.9 \%$ for type- 1 and $0.4 \%$ for type- 2 errors after implementing additional observations in per unit volume of regions outside $\mathrm{A}, \mathrm{B}$, and $\mathrm{C}$, which are much smaller than those of implementing target observations in regions $\mathrm{A}, \mathrm{B}$, and $\mathrm{C}$. In this sense, we regard A, $\mathrm{B}$, and $\mathrm{C}$ as sensitive areas for target observation associated with El Niño predictions. That is to say, implementing additional observation in regions $\mathrm{A}, \mathrm{B}$, and $\mathrm{C}$ could be much greatly to improve the El Niño prediction skill compared to doing this in other regions; furthermore, it would be much economical in terms of the small volume of sensitive area.

\section{Conclusions}

In this study, we use the NCAR's CESM to investigate the initial errors that often cause a significant SPB for El Niño events, under the assumption that the model physics are perfect. From the predictions bestriding spring during the growth phase of El Niño events, two types of initial errors are identified that have significant season-dependent evolutions, with the significant growth occurring in the AMJ or JAS season and large prediction error related to the significant SPB for El Niño events. One of the error types possesses an SSTA component with negative anomalies in the central-eastern equatorial Pacific, plus a basin-wide dipolar pattern in the subsurface temperature anomaly with negative anomalies in the upper layers of the eastern equatorial Pacific and positive anomalies in the lower layers of the western equatorial Pacific. The other type consists of an SSTA component with positive anomalies in the southeastern equatorial Pacific and a large-scale zonal dipole pattern of the subsurface temperature anomaly, with positive anomalies in the upper layers of the eastern equatorial Pacific and negative anomalies in the lower layers of the central-western equatorial Pacific.

In spite of the different patterns of the two types of SPB-related initial errors, both cause El Niño events to be under-predicted. Specifically, both types of SPB-related initial errors exhibit a typical La Niña-like evolving mode, causing a large negative prediction error for El Niño events, despite presenting different behaviors in their early stages of the error growth. In one case, the initial errors grow directly in a manner similar to the growth behavior of a La Niña event; in the other case, the errors initially exhibit a rapid decay of the El Niño-like mode, and then a quick transition to a typical La Niña-like evolving mode. Further investigation suggests that there are two competing factors affecting the SSTA error in the eastern equatorial Pacific. One factor is the Bjerknes positive feedback mechanism, the coupling of the equatorial zonal wind anomalies and changes in SST owing to equatorial upwelling in the eastern Pacific, which causes an intensification of the initial SSTA error. The second factor is the negative feedback mechanism associated with an eastward Kelvin wave from the western tropical Pacific, which leads to weakening of the initial SSTA error over the eastern equatorial Pacific. For the type-1 initial errors, the Bjerknes positive feedback mechanism plays a leading role throughout the error growth; while for the development of the type- 2 errors, the negative feedback initially has a first-order effect, and the role of Bjerknes feedback is moderate, but once a negative SST anomaly over the eastern equatorial Pacific occurs, the Bjerknes feedback becomes dominant and the negative feedback is negligible. Finally, a La Niña-like mode is then quickly established. 
Both type-1 and -2 SPB-related initial errors induce large negative prediction errors of Niño-3 SSTA for El Niño events. Results show that the large prediction errors are mainly attributed to the growth of the initial sea temperature errors in several key regions of the tropical Pacific, which are also consistent with the regions bearing large initial errors. For the type-1 initial errors, the errors in the upper layer of the eastern equatorial Pacific (i.e. regions $\mathrm{A}$ and $\mathrm{B}$ in Fig. 6) tend to make a greater contribution to the final prediction error of Niño-3 SSTA; while for the type-2 initial errors, the prediction errors for Niño-3 SSTA mainly originate from the initial sea temperature errors in the lower layer of the western equatorial Pacific (i.e. region $\mathrm{C}$ in Fig. 6). In particular, when the initial errors in regions $\mathrm{A}$ and $\mathrm{B}$ for the type-1 initial errors and region $\mathrm{C}$ for the type-2 initial errors are eliminated, without changing the initial errors in other regions, the resultant predictions errors normalized by related region's volume are more significantly reduced than those by only removing initial errors outside of $\mathrm{A}, \mathrm{B}$, and $\mathrm{C}$ regions. The regions $\mathrm{A}, \mathrm{B}$, and $\mathrm{C}$ may therefore represent the "sensitive area" for target observation of El Niño predictions. That is to say, if we implement the additional observation in these regions and assimilate them to the initial fields, the El Niño forecasting skill could be greatly improved, as compared to doing so in other regions.

Yu et al. (2009) recognized two types of initial errors using the simple ZC model. These two types of initial errors are of almost opposite sign and cause a significant SPB for El Niño events. One type possesses an SSTA pattern with negative anomalies in the central-western equatorial Pacific, positive anomalies in the eastern equatorial Pacific, and a thermocline depth anomaly pattern with positive anomalies along the equator; while the other type possesses patterns that are almost opposite to those of the former type. To facilitate the following discussion, we refer to the former type as type-A initial errors and the latter type as type-B initial errors (also see Duan et al. 2009). $\mathrm{Yu}$ et al. (2009) illustrated that the type-A and -B initial errors possess dynamic behavior similar to El Niño and La Niña events, and are explained by the Bjerknes positive feedback mechanism. Furthermore, Mu et al. (2014) demonstrated that the precursory perturbations that are most likely to develop into El Niño or La Niña events bear a strong resemblance with the initial errors that induce a significant SPB with the ZC model. This indicates that initial anomalies with the structure of type-A and -B initial errors also act as precursory disturbances for El Niño and La Niña events, respectively (Duan and Wei 2012; Zhang et al. 2014). In the present study, we also obtain two types of SPB-related initial errors (i.e. the type-1 and type-2 initial errors in Fig. 6) for El Niño predictions in the CESM, both of which include not only the SST component but also the subsurface temperature component. However, the type- 1 and -2 initial errors in this study are asymmetrical in pattern, which is not the case in the type-A and -B initial errors in the ZC model. Actually, the type-1 initial errors show negative anomalies in both surface and subsurface layers of the eastern equatorial Pacific, and suggest a pattern comprising negative SST anomalies and a shoaling thermocline in the eastern equatorial Pacific. This pattern mirrors that presented by the type-B initial errors in the ZC model. In spite of asymmetrical pattern, both the type-1 and -2 initial errors exhibit a growth behavior similar to the La Niña evolving mode. Similarly, the initial anomalies with the structure of type- 1 and -2 initial errors could be a precursory disturbance for La Niña events. However, unlike type-1 initial errors that grow directly starting from a cold phase, the type- 2 initial errors experience a decaying period of positive SST anomalies in the eastern equatorial Pacific due to a negative feedback process associated with wave dynamics, and then a transition to a cold phase, followed quickly by growth into a La Niña-like mode because of Bjerknes positive feedback. Therefore, if we regard the initial anomaly with type-2 initial error structure as a precursory disturbance for La Niña, it is clearly preceding the initial anomaly with the type-1 initial error structure (similar to type-B in the ZC model). In other words, the initial anomaly with type- 2 initial error structure may present a much earlier signal for the occurrence of La Niña events, favoring prediction of La Niña events with a much longer lead time. Besides, considering the onset of El Niño and La Niña often occurs in spring due to the fast growth of anomalies in this season (Wang and Fang 1996), we infer that the predictions for a neutral year may also yield SPB phenomenon because of the effect of type- 1 and -2 errors.

\section{Discussions}

To investigate the spatial characteristics of initial errors that cause a significant SPB for El Niño events, we chose the sea temperature differences between a particular month and the start month in the tropical Pacific as initial errors. Therefore, this strategy may not guarantee that the constructed initial errors cover all kinds of realistic initial error patterns. That is to say, the sensitive areas identified in this paper may not consist of all sensitive areas for target observation associated with El Niño predictions. Especially, mounting evidences suggest that El Niño changes and its predictability can also be due to the influence from outside of the tropical Pacific. For example, within the tropic, the variability in the Indian Ocean sector [e.g. Indian Ocean dipole (IOD); Saji et al. 1999] can influence El Niño through both the Indonesian Throughflow and Walker circulation, and the initial conditions of the tropical Atlantic have a stronger impact on the predictability of El 
Niño (Frauen and Dommenget 2012; Keenlyside et al. 2013; Zhou et al. 2015). While, outside of the tropic, SST in the North Pacific, South Atlantic, and South Indian Oceans can offer important source of predictability for El Niño (Boschat et al. 2013). In this sense, these regions may also contain the "sensitive area" for target observations for El Niño predictions.

In this study, we emphasize the role of oceanic initial error pattern in leading to a significant SPB for El Niño events. Some studies also suggested the annual cycle plays a significant role in occurrence of the SPB (Webster and Yang 1992; Moore and Kleeman 1996; Thompson and Battisti 2001). Especially, recently, basing on a damped and noise driven conceptual model, Levine and McPhaden (2015) examined the effectiveness of the annual cycle in producing the SPB and found that only inclusion of the annual cycle of ENSO growth rate gives rise to the SPB phenomenon. And others put an emphasis on the ENSO event itself as well (Samelson and Tziperman 2001). With a conceptual ENSO model, $\mathrm{Mu}$ et al. (2007a) combined above arguments and stated that the SPB may result from combined effect of the annual cycle, the El Niño event itself and the initial error pattern. In particular, Duan et al. (2009) further stressed that even with the annual cycle, there are still some initial errors that can induce SPB while others cannot. Then, in the present study, we just explored the characteristics of those initial errors that induce a significant SPB for El Niño events. Apparently, in addition to the influence from ocean, the prediction skill of El Niño events may also be affected by atmospheric states. With an intermediated coupled model, Zheng and Zhu (2010) have shown that better representation of zonal wind stress anomalies through coupled assimilation can reduce SST forecast errors through improve accuracy of ocean currents. Moreover, increasing studies highlight the potential impact of atmospheric stochastic forcing [e.g. westerly wind burst (WWB)] on the diversity and predictability of El Niño events (Hu et al. 2014; Chen et al. 2015). Particularly, Lopez and Kirtman (2014) indicated the SPB is due to the presence of WWB because significant WWB activities can contribute to a rapid drop off in signal-to-noise ratio of coupled system in spring. Actually, comparison between these studies associated with atmospheric effects and the present study proposes a new question to the SPB: is the SPB more sensitive to ocean state or variations in atmosphere? That is to say, ones should further explore sensitive variables for ENSO predictions and then the associated target observation, which may be much important for improving ENSO forecast skill.

The SPB may also affect the prediction of La Niña. In this paper, we did not pay attention to it because main characteristics of La Niña events, for example, phase locking, cannot be well modeled by the CESM control simulation. Yu et al. (2009) adopted the simple ZC model (Zebiak and Cane 1987) and demonstrated that the SPB-related initial errors associated with the predictions bestriding spring in the growth phase of
El Niño have patterns for SSTA and thermocline depth anomaly components similar to those across spring in the decay phase of El Niño. However, ones do not know whether or not the results from the ZC model are applied to complex coupled GCMs. Therefore, to make it much clear, ones should further explore this question by using CESM or other coupled GCMs.

In addition, it is well-known that there are two types of El Niño events. One type consists of canonical El Niño events, which have their maximum SST anomaly center located in the eastern equatorial Pacific attached to the coast of South America (Rasmusson and Carpenter 1982), and has been referred to as "Eastern Pacific El Niño" (EP-El Niño) (Kao and Yu 2009). The other type is often called "Central Pacific El Niño" (CP-El Niño) (Kao and Yu 2009), in which warm SST is mainly concentrated in the central Pacific and it propagation is weaker and less clear (Ashok et al. 2007; Kao and Yu 2009; Kug et al. 2009). In the present study, we pay more attention on the SPB problem of the EP-El Niño events and identified two types of initial errors that often cause a significant SPB and explored corresponding dynamical mechanisms for error growth and further revealed their implications for target observation of EP-El Niño predictions. However, recent studies have shown that the CP-El Niño events have become more frequent and common than the EP-El Niño during the late twentieth century, especially after the 1990s (Ashok et al. 2007; Kao and Yu 2009; Kug et al. 2009). Unlike the EP-El Niño events, the evolution of CP-El Niño events are mainly due to the zonal advective feedback rather than the thermocline feedback, which may be linked to the shift of the relationship between SST anomalies and WWV anomalies. Since 2000, the lead time between WWV and SST anomalies has decreased from 2 to 3 seasons to only one season (McPhaden 2012). Consequently, for the CP-El Niño, whether there exists the SPB phenomenon? If so, what kind of initial error will be the most likely to cause a significant SPB, and whether it is the same to that of EP-El Niño or not? In fact, the relevant work is currently underway within a simple coupled model and will hopefully be reported in the future, expecting to provide useful information for identifying and predicting two different flavors of El Niño.

Acknowledgments This work was jointly sponsored by the National Basic Research Program of China (Grant No. 2012CB955200), the National Public Benefit (Meteorology) Research Foundation of China (Grant No. GYHY201306018), and the National Natural Science Foundation of China (Grant Nos. 41230420 and 41176013).

Open Access This article is distributed under the terms of the Creative Commons Attribution 4.0 International License (http://creativecommons.org/licenses/by/4.0/), which permits unrestricted use, distribution, and reproduction in any medium, provided you give appropriate credit to the original author(s) and the source, provide a link to the Creative Commons license, and indicate if changes were made. 


\section{References}

AchutaRao K, Sperber KR (2002) Simulation of the El Niño Southern Oscillation: results from the coupled model intercomparsion project. Clim Dyn 19:191-209

Ashok K, Behera SK, Rao SA, Weng HY, Yamagata T (2007) El Niño Modoki and its possible teleconnection. J Geophys Res 112:C11007. doi:10.1029/2006JC003798

Battisti DS, Hirst AC (1989) Interannual variability in the tropical atmosphere/ocean system: influence of the basic state, ocean geometry and nonlinearity. J Atmos Sci 46:1687-1712

Bellenger H, Guilyardi E, Leloup J, Lengaigne M, Vialard J (2014) ENSO representation in climate models: from CMIP3 to CMIP5. Clim Dyn 42:1999-2018. doi:10.1007/s00382-013-1783-z

Bjerknes J (1969) Atmospheric teleconnections from the equatorial pacific. Mon Weather Rev 97(3):163-172

Boschat G, Terray P, Masson S (2013) Extratropical forcing of ENSO. Geophys Res Lett 40:1605-1611. doi:10.1002/grl.50229

Cane MA, Zebiak SE, Dolan SC (1986) Experimental forecasts of El Niño. Nature 321(6073):827-832

Capotondi A (2013) ENSO diversity in the NCAR CCSM4 climate model. J Geophys Res 118:4755-4770. doi:10.1002/jgrc.20335

Chen D, Cane MA (2008) El Niño prediction and predictability. J Comput Phys 227(7):3625-3640. doi:10.1016/j.jcp.2007.05.014

Chen D, Zebiak SE, Busalacchi AJ, Cane MA (1995) An improved procedure for El Niño forecasting-implications for predictability. Science 269:1699-1702

Chen D, Cane MA, Kaplan A, Zebiak SE, Huang DJ (2004) Predictability of El Niño over the past 148 years. Nature 428(6984):733-736

Chen D, Lian T, Fu C, Cane MA, Tang Y, Murtugudde R, Song X, Wu Q, Zhou L (2015) Strong influence of westerly wind bursts on El Niño diversity. Nat Geosci 8:339-345. doi:10.1038/NGEO2399

Clarke AJ, Van Gorder S (2003) Improving El Niño prediction using a space-time integration of Indo-Pacific winds and equatorial Pacific upper ocean heat content. Geophys Res Lett 30(7):1399. doi:10.1029/2002GL016673

Craig AP, Vertenstein M, Jacob R (2012) A new flexible coupler for earth system modeling developed for CCSM4 and CESM1. Int J High Perform Comput Appl 26(1):31-42. doi: $10.1177 / 1094342011428141$

Duan WS, Wei C (2012) The 'spring predictability barrier' for ENSO predictions and its possible mechanism: results from a fully coupled model. Int J Climatol 33(5):1280-1292. doi:10.1002/ joc. 3513

Duan WS, Liu XC, Zhu KY, Mu M (2009) Exploring the initial errors that cause a significant "spring predictability barrier" for El Niño events. J Geophys Res 114:C04022. doi:10.1029/2008JC004925

Frauen C, Dommenget D (2012) Influences of the tropical Indian and Atlantic Oceans on the predictability of ENSO. Geophys Res Lett 39:L02706. doi:10.1029/2011GL050520

Hasegawa T, Hanawa K (2003) Heat content variability related to ENSO events in the Pacific. J Phys Oceanogr 33(2):407-421

Hoerling MP, Kumar A, Zhong M (1997) El Niño, La Niña, and the nonlinearity of their teleconnections. J Clim 10(8):1769-1786

Hu S, Fedorov AV, Lengaigne M, Guilyardi E (2014) The impact of westerly wind bursts on the diversity and predictability of El Niño events: an ocean energetics perspective. Geophys Res Lett 41:4654-4663. doi:10.1002/2014GL059573

Hunke EC, Lipscomb WH (2008) CICE: the Los Alamos sea ice model, documentation and software, version 4.0. Los Alamos National Laboratory Tech. Rep. LACC-06-012, 76 pp

Hurrell JW, Holland MM, Gent PR, Ghan S, Kay JE, Kushner PJ, Lamarque JF, Large WG, Lawrence D, Lindsay K, Lipscomb WH, Long MC, Mahowald N, Marsh DR, Neale RB, Rasch P,
Vavrus S, Vertenstein M, Bader D, Collins WD, Hack JJ, Kiehl J, Marshall S (2013) The community earth system model a framework for collaborative research. Bull Am Meteorol Soc 94(9):1339-1360. doi:10.1175/BAMS-D-12-001211

Jin FF (1997a) An equatorial ocean recharge paradigm for ENSO. Part I: conceptual model. J Atmos Sci 54(7):811-829

Jin FF (1997b) An equatorial ocean recharge paradigm for ENSO. Part II: a stripped-down coupled model. J Atmos Sci 54(7):830-847

Jin EK, Kinter JL, Wang B, Park CK, Kang IS, Kirtman BP, Kug JS, Kumar A, Luo JJ, Schemm J, Shukla J, Yamagata T (2008) Current status of ENSO prediction skill in coupled ocean-atmosphere models. Clim Dyn 31(6):647-664

Kao HY, Yu JY (2009) Contrasting eastern-Pacific and central-Pacific types of ENSO. J Clim 22(3):615-632

Keenlyside NS, Ding H, Latif M (2013) Potential of equatorial Atlantic variability to enhance El Niño prediction. Geophys Res Lett 40:2278-2283. doi:10.1002/grl.50362

Kirtman BP, Shukla J, Balmaseda M, Graham N, Penland C, Xue Y, Zebiak S (2002) Current status of ENSO forecast skill: a report to the Climate Variability and Predictability (CLIVAR) Numerical Experimentation Group (NEG). CLIVAR working group on seasonal to interannual prediction. http://www.clivar.org/publications/wgpreports/wgsip/nino3/report.htm

Kug JS, Jin FF, An SI (2009) Two types of El Niño events: cold tongue El Niño and warm pool El Niño. J Clim 22(6):1499-1515

Latif M, Barnett TP, Cane MA, Flugel M, Graham NE, Vonstorch H, Xu JS, Zebiak SE (1994) A review of ENSO prediction studies. Clim Dyn 9:167-179

Latif M, Anderson D, Barnett T, Cane M, Kleeman R, Leetmaa A, O'Brien J, Rosati A, Schneider E (1998) A review of the predictability and prediction of ENSO. J Geophys Res 103(C7):1437514393. doi: $10.1029 / 97 J C 03413$

Levine AFZ, McPhaden MJ (2015) The annual cycle in ENSO growth rate as a cause of the spring predictability barrier. Geophys Res Lett 42:1-8. doi:10.1002/2015GL064309

Lipscomb WH, Fyke JG, Vizcaino M, Sacks WJ, Wolfe J, Vertenstein M, Craig A, Kluzek E, Lawrence DM (2013) Implementation and initial evaluation of the glimmer community ice sheet model in the community earth system model. J Clim 26(19):7352-7371

Lopez H, Kirtman KP (2014) WWBs, ENSO predictability, the spring barrier and extreme events. J Geophys Res Atmos 119:1011410138. doi:10.1002/2014JD021908

Luo JJ, Masson S, Behera S, Shingu S, Yamagata T (2005) Seasonal climate predictability in a coupled OAGCM using a different approach for ensemble forecasts. J Clim 18(21):4474-4497

Luo JJ, Masson S, Behera SK, Yamagata T (2008) Extended ENSO predictions using a fully coupled ocean-atmosphere model. J Clim 21(1):84-93

McPhaden MJ (2003) Tropical Pacific Ocean heat content variations and ENSO persistence barriers. Geophys Res Lett 30(9):1480. doi:10.1029/2003GL016872

McPhaden MJ (2012) A 21st century shift in the relationship between ENSO SST and warm water volume anomalies. Geophys Res Lett 39:L09706. doi:10.1029/2012GL051826

Meinen CS, McPhaden MJ (2000) Observations of warm water volume changes in the equatorial Pacific and their relationship to El Niño and La Niña. J Clim 13(20):3551-3559

Moore AM, Kleeman R (1996) The dynamics of error growth and predictability in a coupled model of ENSO. Q J R Meteorol Soc 122:1405-1446

Mu M (2013) Methods, current status, and prospect of targeted observation. Sci China Earth Sci 56(12):1997-2005

Mu M, Duan WS, Wang B (2003) Conditional nonlinear optimal perturbation and its applications. Nonlinear Process Geophys 10(6):493-501 
Mu M, Duan WS, Wang B (2007a) Season-dependent dynamics of nonlinear optimal error growth and El Niño-Southern Oscillation predictability in a theoretical model. J Geophys Res 112:D10113. doi:10.1029/2005JD006981

Mu M, Xu H, Duan WS (2007b) A kind of initial errors related to "spring predictability barrier" for El Niño events in ZebiakCane model. Geophys Res Lett 34:L03079. doi:10.1029/200 6GL027412

Mu M, Yu YS, Xu H, Gong TT (2014) Similarities between optimal precursors for ENSO events and optimally growing initial errors in El Niño predictions. Theor Appl Climatol 115:461-469

Neale RB, Chen CC, Gettelman A et al (2012) Description of the NCAR Community Atmosphere Model (CAM 5.0). NCAR Tech. Note TN-486, $274 \mathrm{pp}$

Oleson KW, Lawrence DM, Bonan GB et al (2010) Technical description of version 4.0 of the Community Land Model (CLM). NCAR Tech. Note NCAR/TN-478 + STR, 257 pp

Philander SGH (1983) El Niño Southern Oscillation phenomena. Nature 302(5906):295-301

Philander SGH (1990) El Niño, La Niña and the Southern Oscillation. Academic Press, London

Picaut J, Masia F, duPenhoat Y (1997) An advective-reflective conceptual model for the oscillatory nature of the ENSO. Science 277(5326):663-666

Ramesh N, Murtugudde R (2013) All flavours of El Niño have similar early subsurface origins. Nat Clim Change 3:42-46

Rasmusson EM, Carpenter TH (1982) Variations in tropical seasurface temperature and surface wind fields associated with the Southern Oscillation/El Niño. Mon Weather Rev 110(5):354-384

Ropelewski CF, Halpert MS (1987) Global and regional scale precipitation patterns associated with the El Niño Southern Oscillation. Mon Weather Rev 115(8):1606-1626

Rutt IC, Hagdorn M, Hulton NRJ, Payne AJ (2009) The glimmer community ice sheet model. J Geophys Res 114:F02004. doi:10. 1029/2008GF001015

Saji NH, Goswami BN, Vinayachandran PN, Yamagata $\mathrm{T}$ (1999) A dipole mode in the tropical Indian Ocean. Nature 401(6751):360-363

Samelson RM, Tziperman E (2001) Instability of the chaotic ENSO: the growth-phase predictability barrier. J Atmos Sci 58(23):3613-3625

Smith R, Jones P, Briegleb B et al (2010) The Parallel Ocean Program (POP) reference manual: ocean component of the Community Climate System Model (CCSM) and Community Earth System Model (CESM). Los Alamos National Laboratory Tech. Rep. LAUR-10-01853, $141 \mathrm{pp}$

Snyder C (1996) Summary of an informal workshop on adaptive observations and FASTEX. Bull Am Meteorol Soc 77:953-961

Suarez MJ, Schopf PS (1988) A delayed action oscillator for ENSO. J Atmos Sci 45(21):3283-3287

Thompson C, Battisti D (2001) A linear stochastic dynamical model of ENSO. Part II: analysis. J Clim 14(4):445-466

Torrence C, Webster PJ (1998) The annual cycle of persistence in the El Niño Southern Oscillation. Q J R Meteorol Soc 124(550):1985-2004

Trenberth KE, Branstator GW, Karoly D, Kumar A, Lau NC, Ropelewski C (1998) Progress during TOGA in understanding and modeling global teleconnections associated with tropical sea surface temperatures. J Geophys Res 103(C7):14291-14324. doi:10.1029/97jc01444
Wang B, Fang Z (1996) Chaotic oscillation of tropical climate: a dynamic system theory for ENSO. J Atmos Sci 53:2786-2802

Wang CZ, Fiedler PC (2006) ENSO variability and the eastern tropical Pacific: a review. Prog Oceanogr 69:239-266

Wang CZ, Picaut J (2004) Understanding ENSO physics-a review. Earth climate: the ocean-atmosphere interaction. Geophys Monogr Am Geophys Union 147:21-48

Webster PJ (1995) The annual cycle and the predictability of the tropical coupled ocean-atmosphere system. Meteorol Atmos Phys 56:33-55

Webster PJ, Yang S (1992) Monsoon and ENSO: selectively interactive systems. Q J R Meteorol Soc 118(507):877-926

Weisberg RH, Wang CZ (1997) A western Pacific oscillator paradigm for the El Niño Southern Oscillation. Geophys Res Lett 24(7):779-782

Wyrtki K (1975) El Niño-the dynamic response of the equatorial Pacific Ocean to atmospheric forcing. J Phys Oceanogr 5:572-584

Wyrtki K (1985) Water displacements in the pacific and the genesis of El Niño cycles. J Geophys Res 90(C4):7129-7132

Xue Y, Cane MA, Zebiak SE, Blumenthal MB (1994) On the prediction of ENSO: a study with a low-order Markov model. Tellus A 46(4):512-528

Xue Y, Cane MA, Zebiak SE (1997a) Predictability of a coupled model of ENSO using singular vector analysis. Part I: optimal growth in seasonal background and ENSO cycles. Mon Weather Rev 125(9):2043-2056

Xue Y, Cane MA, Zebiak SE (1997b) Predictability of a coupled model of ENSO using singular vector analysis. Part II: optimal growth and forecast skill. Mon Weather Rev 125(9):2057-2073

Yu JY, Kao HY (2007) Decadal changes of ENSO persistence barrier in SST and ocean heat content indices: 1958-2001. J Geophys Res 112:D13106. doi:10.1029/2006jd007654

Yu YS, Duan WS, Xu H, Mu M (2009) Dynamics of nonlinear error growth and season-dependent predictability of El Niño events in the Zebiak-Cane model. Q J R Meteorol Soc 135:2146-2160

Yu YS, Mu M, Duan WS, Gong TT (2012) Contribution of the location and spatial pattern of initial error to uncertainties in El Niño predictions. J Geophys Res 117:C06018. doi:10.1029/201 1JC007758

Zebiak SE (1989) Oceanic heat-content variability and El Niño cycles. J Phys Oceanogr 19(4):475-486

Zebiak SE, Cane MA (1987) A model El Niño Southern Oscillation. Mon Weather Rev 115(10):2262-2278

Zelle H, Appeldoorn G, Burgers G, van Oldenborgh GJ (2004) The relationship between sea surface temperature and thermocline depth in the eastern equatorial Pacific. J Phys Oceanogr 34(3):643-655

Zhang T, Sun DZ (2014) ENSO asymmetry in CMIP5 models. J Clim 10(27):4070-4093

Zhang J, Duan WS, Zhi XF (2014) Using CMIP5 model outputs to investigate the initial errors that cause the "spring predictability barrier" for El Niño events. Sci China Earth Sci 57:1-6

Zheng F, Zhu J (2010) Coupled assimilation for an intermediated coupled ENSO prediction model. Ocean Dyn 60(5):1061-1073

Zhou Q, Duan WS, Mu M, Feng R (2015) Influence of positive/negative Indian Ocean Dipole on Pacific ENSO through Indonesian throughflow: results from sensitivity experiments. Adv Atmos Sci 32(6):783-793 